\title{
Foot measurements from 3-dimensional scans: A comparison and evaluation of different methods
}

Channa P. Witana, Shuping Xiong, Jianhui Zhao and Ravindra S. Goonetilleke*

\author{
Human Performance Laboratory \\ Department of Industrial Engineering and Logistics Management \\ Hong Kong University of Science and Technology \\ Clear Water Bay, Hong Kong
}

*Contact Information

Telephone: (852)-2358-7109

Fax: (852)-2358-0062

Email: ravindra@ust.hk 


\section{Abstract}

An approach to automatic foot measurement using 3D scanned data is proposed in this paper. The proposed approach was evaluated through comparisons of simulated measurements (SM) of eleven male and nine female participants with manual measurements and with the output of a commercially available automated foot measuring system (CP). The registration procedure for the measurements and unambiguous definitions for each measurement were first established. Eighteen dimensions of each foot were calculated from the scanned data that comprised point clouds and selected landmarks. Two operators manually measured each participant's foot twice. These manual measurements (MM) showed high inter- and intra-operator reliability (ICC $>0.84)$. Ten of the eighteen dimensions obtained from the three measurement methods, SM, CP, and MM, were subjected to an ANOVA and eight of the measurements showed significant differences among the three methods. After establishing a linear correction to adjust for systematic errors, there were no significant differences between the SM and MM methods for 17 of the 18 foot dimensions; and the single exception was the heel width dimension. The differences among the three methods, correction procedures and their significance are discussed.

Relevance to industry: Measuring feet to obtain the relevant dimensions that characterize feet can be quite tedious and the measurement may be dependent on the 
measurer. Automatic measurement with scanned data on the other hand, can give replicable information even though the measurements depend on the intricacies of the scanning system and the computational algorithms adopted. The proposed definitions and algorithms provide a means to automate foot measurements for customized footwear.

Keywords: Foot measurement, simulated measurement, anthropometry, measurement error, foot scan, body measurement, measurement reliability. 


\section{Introduction}

Lengths, widths, heights and girths of feet should match with those of shoes in order for footwear to be comfortable (Clarks, 1976; White, 1982; Pivečka and Laure, 1995; Venkatappaiah, 1997). There are many studies on foot anthropometry that describe different techniques to measure critical dimensions on feet (Freedman et al., 1946; Rossi, 1983; Hawes and Sovak, 1994; Kouchi, 2003; Bunch, 1988; Liu et al., 1999). In terms of technology development, there has been an exponential growth in laser scanner technologies with various applications in recent years (Blais et al., 2000; Gärtner et al., 1999; Houle et al., 1997; Wehr, 1999) that claim accuracy within $1 \mathrm{~mm}$. The basic principle of scanning technology is triangulation in order to generate the surface coordinates that make the shape. The captured information is then processed and curve-fitting techniques are used to obtain the surface coordinates, sometimes after processing for known errors in the system (Carocci et al., 1997). The accuracy of the scanner itself can vary depending on the object that is scanned and the method used for scanning. In general, a human foot can be modeled using several "slices" of scanned data obtained along the length of the foot (Luximon and Goonetilleke, 2004). As a result, it is now possible to obtain surface information to make customized products such as shoes (Viavor, 2005). Even though foot scanners capture shape information, it is difficult to include all the shape information in a shoe last design. Footwear 
manufacturers still resort to matching linear and girth dimensions to achieve the right fit. Consequently, measurements play an important role in footwear manufacturing. With non-uniform surfaces, such as feet, the scanner manufacturer's specifications of accuracy may not be suitable for the measurements that are required to make footwear. In addition, body sway during scanning can affect image fidelity and thereby affect the captured information and the accuracy (Corner and $\mathrm{Hu}, 1997)$. Thus the objectives of this study were:

1. to obtain inter-operator and intra-operator reliability in manual foot measurements (MM) and

2. to compare $\mathrm{MM}$ with measurements obtained from the scanner software (commercial program, CP), and measurements calculated from the algorithms we developed (simulated measurements, SM).

\section{Methodology}

\subsection{Participants}

Twenty students (11 males and 9 females) from the Hong Kong University of Science and Technology were recruited for this experiment. None of them had any visible foot abnormalities or foot illnesses. It is possible that there are differences unique to gender. In order to eliminate any such effect, both males and females were participants. The 
descriptive statistics of the participants are given in Table 1.

[Insert Table 1 Here]

\subsection{Equipment}

The YETI ${ }^{\mathrm{TM}}$ I foot scanner (Vorum Research Corporation, 2000) was used to obtain the 3D shape of the foot. The scanner system has been designed to collect surface data on a number of slices along the length of the foot. Four lasers shine a line of light on the surface. Eight cameras then capture images of the reflected laser light at each section along the surface. The camera images are then used to determine the $3 \mathrm{D}$ coordinates of the points at each section.

\subsection{Experimental Design}

A "repeated measures" design (Montgomery, 2001) was used with the dependent variables being measurements obtained on the right-foot of each participant. The independent variable was the method of measurement at three levels, MM, SM, and CP.

\subsection{Experimental Procedure}




\subsubsection{Manual foot measurements}

The methods used were in accordance with the guidelines set forth by the committee on research practice at the Hong Kong University of Science and Technology. The participants' feet were disinfected and dried prior to measuring. Two operators measured 18 dimensions (Figure 1, Table 2) on each person's right foot twice (2 operators x 2 trials) using set squares, a measuring tape and calipers. There were four MM readings for each subject's right foot. The order of measurement between operators 1 and 2 was random. Each participant was asked to stand on a platform with equal weight on each foot (Figure 2). The posterior point of the heel (pternion) touched the measuring device plate. The foot was then rotated around pternion so that the distance between the location at landmark-1 (Figure 3) and the centerline (or X-axis) of the transparency (Figure 2) was $38.1 \mathrm{~mm}$ (1.5 inches). The alignment thus obtained matches with that of a Brannock device (Brannock, 2005), which has been a tool used for measuring feet in the US for a number of years. Researchers have adopted differing definitions for the foot axis (X-axis). The most common of these is the line joining the pternion and the tip of the second toe (Kouchi, 2003). An axis determined this way is sensitive to deformation of the second toe, such as feet with bunions. Thus, lengths and widths of feet with bunions and those without bunions will be significantly different with a pternion-to-second toe tip axis measurement even though the feet are similar, 
except in the toe region. The Brannock axis, which is $38.1 \mathrm{~mm}$ (1.5 inches) from the medial side of the first metatarsal bone, was used as the $\mathrm{x}$-axis to eliminate any such "noisy" variation.

\section{[Insert Figures 1, 2, 3 \& Table 2 about here]}

\subsubsection{Foot landmarking and scanning}

After obtaining the measurements manually (MM) four times, the participant's right foot was laser scanned in order to obtain the corresponding SM and CP measurements. Prior to the scanning, ten anatomical landmarks were identified and marked on the right foot. Five of those landmarks were on the top of metatarsal-phalangeal joints (MPJ), one each at the side of the first and fifth MPJ, one each on the medial and lateral malleolus, and one at the arch point (Figure 3). Then, the participant's right foot was aligned and scanned on the foot scanner with half-body-weight on each foot. After the scanning, the scanned points and the ten landmarks were stored as a point cloud. Since the scanned sections were set to be $1 \mathrm{~mm}$ apart and each section had 360 points, the total number of points was dependent on the foot length.

\subsubsection{Simulated foot measurements}


The foot scan data were thereafter processed using the YETI Shape Builder software version 4.1.0.95 (CP) and also using our program (SM) developed using $\mathrm{C}++$ (Section 3). Out of the 18 foot dimensions (Table 2), only ten (foot length, arch length, heel-to-medial malleolus, heel-to-lateral malleolus, foot width, medial malleolus height, lateral malleolus height, ball girth, instep girth and short heel girth) were available in the commercial software system. Those ten measurements are henceforth referred to as the "common measurements" and the other eight measurements (heel-to-fifth toe length, heel width, bimalleolar width, mid-foot width, height at $50 \%$ of the foot length, long heel girth, ankle girth and waist girth) are referred to as "other measurements".

\section{Algorithms}

\subsection{Foot Registration}

Registration was used to minimize variations due to misalignment. The same alignment as in the manual measurement was adopted to transform each foot scan prior to measurement as follows:

1) All scanned points no more than $25 \mathrm{~mm}$ above the platform were first selected.

2) These points were then projected on to the XY plane (Figure 4). For every scanned section, the two points on the boundary of the XY projection (points with minimum 
Y coordinate and maximum Y coordinate) were then found.

3) A second degree polynomial $x=a * y^{2}+b * y+c$ was fitted for the points on the boundary of $\mathrm{XY}$ projection and within $25 \mathrm{~mm}$ from the heel point along the $\mathrm{X}$-axis in order to generate the heel curve (Figure 4).

4) The pternion $\left(x_{P}, y_{P}\right)$ was determined from $x_{P}=\left(4 * a * c-b^{2}\right) /(4 * a)$ and $y_{P}=-b /(2 * a)$.

5) The distance, $d_{P-M 1}$, between the pternion point and landmark-1 $\left(x_{M 1}, y_{M 1}\right)$ in the XY plane was calculated from $d_{P-M 1}=\sqrt{\left(x_{P}-x_{M 1}\right)^{2}+\left(y_{P}-y_{M 1}\right)^{2}}$.

6) The distance, $d_{M 1}$, between landmark-1 and the line parallel to the X-axis running through the pternion was calculated from $d_{M 1}=\left|y_{P}-y_{M 1}\right|$.

7) The foot was rotated around the pternion and parallel with the XY plane through an angle $\theta=\sin ^{-1}\left(d_{M 1} / d_{P-M 1}\right)-\sin ^{-1}\left(38.1 / d_{P-M 1}\right)$, to make the distance from landmark-1 to the line parallel with $\mathrm{X}$ axis and across the pternion equal $38.1 \mathrm{~mm}$ in order to maintain the same alignment as the Brannock device (Brannock, 2005).

\section{[Insert figure 4 about here]}

Figure 4 shows the point cloud data before and after the alignment procedure. 


\subsection{Determination of Dimensions}

\subsubsection{Length}

Foot length is calculated as the distance between the minimum $\mathrm{X}$ value (mean of five minimum points) and the maximum $X$ value (mean of five maximum points) along the X-axis:

$L_{F L}=\left|x_{\min }-X_{\max }\right| \cdot$

Arch length is calculated as the distance between the point with the minimum $\mathrm{X}$ value (mean of five minimum points) and landmark-1 (Figure 3) along the $\mathrm{X}$-axis:

$L_{A L}=\left|x_{\min }-x_{M 1}\right|$

The heel to medial malleolus length is calculated as the distance between the point with the minimum $\mathrm{X}$ value (mean of five minimum points) and landmark-8 (Figure 3 ) along the X-axis:

$L_{H M M}=\left|x_{\min }-x_{M 8}\right|$.

The heel to lateral malleolus length is calculated as the distance between the point with the minimum $\mathrm{X}$ value (mean of five minimum points) and landmark-9 (Figure 3) along the $\mathrm{X}$-axis: 
$L_{H L M}=\left|X_{\min }-X_{M 9}\right|$.

The heel to fifth toe length is calculated as the distance between the point with minimum $\mathrm{X}$ value (mean of five minimum points) and the fifth toe along the $\mathrm{X}$-axis: $L_{H T S}=\left|X_{\min }-x_{T S}\right|$.

The location of the fifth toe was determined using the inflection point characteristic. The shape of the boundary points projected on to the XY plane on the lateral side of the forefoot vary smoothly until the inflexion point at the tip of the fifth toe (Figure 5). The algorithm for locating the fifth toe is as follows:

1) Project the point cloud onto the $X Y$ plane; for every scanned section, find two points on the boundary of the $\mathrm{XY}$ projection (the point with the minimum $\mathrm{Y}$ value and the point with the maximum Y value).

2) Consider the lateral boundary points ahead of landmark- $7^{1}$ (along the $X$-axis) (Figure 3) and on the lateral side of landmark-5 (along the Y-axis). i.e., the lateral boundary points of the region bounded by two straight lines as shown in Figure 5(a).

3) Take the point with the minimum $X$ value as the first boundary point, which is on the lateral side of the $\mathrm{i}^{\text {th }}$ section, and then find the next four boundary points.

4) Fit a straight line, $y=a x+b$ for these five points using the least squares method, and

\footnotetext{
${ }^{1}$ Landmark-5 may be more suited to eliminate any possibility of error due to curvatures near the fifth toe.
} 
take $a$ as the starting gradient.

5) Take the boundary point of the $(i+1)^{\text {th }}$ section as the first boundary point; update $i$ as $\mathrm{i}=\mathrm{i}+1$; then find the next four boundary points; and then fit a straight line, $(y=a * x+b)$, for these five points using the least squares method.

6) Repeat Step 5 until the difference between the updated gradient value (a) and the starting gradient value is greater than 0.5 .

7) Repeat Step 5 until the updated gradient value (a) is less than the gradient value of the previous iteration, and take the boundary point of the $i^{\text {th }}$ section as the tip of the fifth toe, as shown in the right of Figure 5.

\section{[Insert figure 5 about here]}

\subsubsection{Width}

Foot width is calculated as the distance between the point with the minimum Y value and the point with the maximum Y value along the Y-axis of the fore-foot (the area in which all points are ahead of landmark-7 (along the X-axis)). The mean of five points were used to determine both the minimum and maximum values in order to minimize the effects of "noise" in the scanned points: 
$W_{F W}=\left|y_{f_{-} \min }-y_{f_{-} \max }\right| \cdot$

Heel width is calculated as the distance between the point with the minimum $\mathrm{Y}$ value (mean of five minimum points) and the point with the maximum $\mathrm{Y}$ value (mean of five maximum points) along the Y-axis in the rear-foot region, i.e. points within $40 \mathrm{~mm}$ from pternion along $\mathrm{X}$-axis and no more than $20 \mathrm{~mm}$ above the platform:

$W_{H W}=\left|y_{h_{-} \min }-y_{h_{-} \max }\right|$.

Bimalleolar width is calculated as the distance between landmark- 8 and landmark- 9 along the Y-axis:

$W_{B W}=\left|y_{M 8}-y_{M 9}\right|$.

Mid-foot width is calculated as the distance along the Y-axis between the minimum $\mathrm{Y}$ value (mean of five minimum points) and the maximum $\mathrm{Y}$ value (mean of five maximum points) at the foot center; i.e., points within a slab of half-thickness of 0.6 $\mathrm{mm}$ on either side of $50 \%$ of the foot length along the $\mathrm{X}$-axis:

$W_{M F}=\left|y_{m_{-} \min }-y_{m_{-} \max }\right|$.

\subsubsection{Height}


Medial malleolus height is calculated as the distance along the Z-axis from the platform (mean of five maximum $\mathrm{Z}$ points) to landmark-8 (the positive $\mathrm{Z}$-axis is pointing downwards, and hence the scanner platform has the maximum $\mathrm{Z}$ value, see Figure 3):

$$
H_{M M}=\left|z_{\max }-Z_{M 8}\right|
$$

Lateral malleolus height is calculated as the distance along the Z-axis between the platform (mean of five maximum $\mathrm{Z}$ points) and landmark-9:

$$
H_{L M}=\left|z_{\max }-z_{M 9}\right| \text {. }
$$

The height at $50 \%$ of the foot length is calculated as the distance along the Z-axis from the platform (mean of five maximum $\mathrm{Z}$ points) to the minimum $\mathrm{Z}$ value (mean of five minimum points) at $50 \%$ of the foot length: i.e., points within a slab of $\pm 0.6 \mathrm{~mm}$ distance from $50 \%$ of the foot length along $\mathrm{X}$-axis:

$$
H_{M F}=\left|z_{\max }-z_{m_{-} \min }\right| \cdot
$$

\subsubsection{Girth}

Traditionally, custom footwear manufacturers use a tape measure to determine girth.

However, the tape does not have contact with the full foot due to the uneven contours on the foot. When the tape is stretched around the foot, there are apertures between the tape 
and the skin surface. In order to simulate such a measurement, convex hulls were used. In computational geometry, a convex hull of a set of points is defined as the smallest convex set containing the points. Berg et al. (1997) described a 2D convex hull like when an elastic rubber band is put around a series of nails. When the rubber band is let go, it will then snap around the nails, minimizing its length, making a convex hull. To determine the girth, the intersection points between the tape plane and the point cloud are first determined and transformed to be parallel with one plane of the 3D coordinate system. Then, a 2D convex hull is constructed and the girth is calculated as the sum of the distances between two neighboring points on the convex hull.

\section{[Insert figure 6 about here]}

As illustrated in Figure 6(a), three control points locate the tape plane, and T1 are the intersection points between the tape plane and the point cloud in the $\mathrm{XY}, \mathrm{XZ}$ and $\mathrm{YZ}$ planes respectively. The intersection points (T1) are then rotated around one control point to be parallel with the XY plane (from T1 to T2), then rotated around the control point to be parallel with the $\mathrm{XZ}$ plane (from $\mathrm{T} 2$ to $\mathrm{T} 3$ ), and then rotated around the control point to be parallel with the YZ plane (from T3 to T4). Thus the intersection points are transformed to be parallel with the $\mathrm{XY}$ plane and only the $\mathrm{X}$ and $\mathrm{Y}$ 
coordinates are considered when the 2D convex hull method is used for girth calculations. The points in Figure 6(b) are an example of the transformed intersection points (i.e., T4), and the corresponding convex hull generated for tape measurement simulation. Girth measurements on the foot are shown in Figure 7.

\section{[Insert figure 7 about here]}

The ball girth is calculated from the intersection points between the point cloud and the tape plane determined by landmark-1, landmark-2 and landmark-7.

The instep girth is calculated from the intersection points between the point cloud and the tape plane determined by the three control points, P1, P2 and P3.

The long heel girth is calculated from the intersection points between the point cloud and the tape plane perpendicular to the $\mathrm{XZ}$ plane and located by two control points, $\mathrm{P} 3$ and P4.

The short heel girth is calculated from the intersection points between the point cloud and the tape plane perpendicular to the $\mathrm{XZ}$ plane and located by two control points, $\mathrm{P} 5$ and P6.

The ankle girth is calculated from the intersection points between the point cloud and the tape plane parallel to the XY plane and located by one control point, P6. 
The waist girth is calculated from the intersection points between the point cloud and the tape plane parallel to the YZ plane and located by the midpoint of landmark-1 and one control point, P1.

The control points, $\mathrm{P} 1$ to $\mathrm{P} 6$ are identified as follows:

1) Control point $\mathrm{P} 1$ is the arch point, i.e. landmark-10 (Figure 3 ).

2) Project the points no more than $20 \mathrm{~mm}$ above the platform to $X Y$ plane and find points on the lateral boundary of the $\mathrm{XY}$ projection (the point with maximum $\mathrm{Y}$ value) of every scanned section.

3) Calculate the distance between P1 and every boundary point on the lateral side from $25 \%$ to $45 \%$ of the foot length, and take the boundary point with the minimum distance as control point P2, as shown in the upper left of Figure 8.

4) Project the point cloud to the $X Z$ plane, and for every scanned section, find the highest point on the boundary of the $\mathrm{XZ}$ projection (the point with the minimum $\mathrm{Z}$ value).

5) Calculate the girth from $\mathrm{P} 1, \mathrm{P} 2$ and every point on boundary of the $\mathrm{XZ}$ projection within $40 \%$ to $55 \%$ of the foot length, and take the boundary point with the minimum girth as control point P3, as shown in the upper right of Figure 8.

6) Calculate the girth perpendicular to the XZ plane and located by P3 and the lowest points on the boundary of the $\mathrm{XZ}$ projection (point with the maximum $\mathrm{Z}$ value of 
every section) from $0 \%$ to $3.5 \%$ of the foot length, and take the boundary point with the maximum girth as control point $\mathrm{P} 4$, as shown in the lower left of Figure 8.

7) Find the first (along the $\mathrm{X}$-axis) lowest point on the boundary of the $\mathrm{XZ}$ projection and another boundary point that just touches the platform, and take the midpoint of these two as control point P5.

8) Calculate the girth perpendicular to the XZ plane and located by P5 and all the highest points on the boundary of the $\mathrm{XZ}$ projection (within the region from $50 \%$ of the foot length to the front of the leg), and take the boundary point with the minimum girth as control point P6, as shown in the lower right of Figure 8.

\section{[Insert figure 8 about here]}

\section{Results}

\subsection{Inter-operator and intra-operator reliabilities}

The inter-operator and intra-operator reliabilities for all manual foot measurements were calculated using intraclass correlation coefficients (ICC), type $(2,1)$ (Shrout and Fleiss, 1979; Webster et al., 2005). The inter-operator reliability, $\operatorname{ICC}(2,1)$ for all 18 manual 
measurements was within the range of 0.920 to 1.000 and the intra-operator reliability, $\operatorname{ICC}(2,1)$ for operator 1 was within the range of 0.841 to 0.998 and for operator 2 within the range of 0.943 to 0.998 (Table 3).

\section{[Insert Table 3 Here]}

\subsection{Measurement Comparisons}

Our pre-experimental data analysis revealed significant differences between SM and MM for most foot dimensions, even though the variations in the differences were relatively small (standard deviations were generally within $1 \mathrm{~mm}$ except in the girth measurements). To investigate the potential presence of any systematic errors between SM and MM, the 20 participants were randomly grouped into a ten-participant "training data set" and a ten-participant "test data set". The two data sets were used for two purposes:

(1) to quantify the systematic errors between SM and MM using the training data set and to use the quantified systematic errors to adjust SM and validate the results with the test data set and

(2) to compare the three measurement methods, CP, SM and MM. 
Homogeneity of variance was checked using the Bartlett test (Bartlett, 1937). There were no significant differences among the different methods in both the training and test data sets at the $\mathrm{p}=0.05$ level.

The training data set was subjected to a linear regression $\left(\mathrm{SM}=\mathrm{a}^{*} \mathrm{MM}+\mathrm{b}\right)$ followed by $(\mathrm{SM}=\mathrm{MM}+\mathrm{b})$ in order to find any systematic errors between $\mathrm{SM}$ and $\mathrm{MM}$. The SM results extracted from the test data set were adjusted based on calculated linear regression models. Descriptive statistics of all 18 measurements obtained from the three methods (MM, SM and CP) for the training and test data sets are given in tables 4 and 5 . A two-way (Measurement Method * Participant) analysis of variance (ANOVA) with post-hoc Student Newman-Keuls (SNK) tests and a paired t-test were conducted to compare the measurement methods. The following statistical model was used (Montgomery, 2001) for testing the ten common measurements:

$\mathrm{Y}_{\mathrm{ij}}=\mu+\tau_{\mathrm{i}}+\beta_{\mathrm{j}}+\varepsilon_{\mathrm{ij}} \quad \mathrm{i}=1, \ldots 3$ and $\mathrm{j}=1, \ldots 10$

where $Y_{i j}$ is the magnitude of each foot measurement of the $j^{\text {th }}$ subject from the $i^{\text {th }}$ measuring method; $\tau_{\mathrm{i}}$ is the effect of the $\mathrm{i}^{\text {th }}$ measuring method and assumed to be a fixed factor; $\beta_{\mathrm{j}}$ is the effect associated of the $\mathrm{j}^{\text {th }}$ subject and a random factor; $\varepsilon_{\mathrm{ij}}$ is the random error. The test static for the measuring method $(\mathrm{df}=2)$ was $\mathrm{F}=\mathrm{MS}_{\text {measuring method }} / \mathrm{MS}_{\text {error }}$ with $\mathrm{MS}_{\text {error }}$ having 18 degrees of freedom. The SAS statistical package was used for all the statistical analyses and all statistical significance levels were set at 0.05 . 


\section{[Insert Table 4 \& Table 5 Here]}

\subsubsection{Comparisons within the training data set}

Since the reliability of MM was relatively high, SM and CP were compared with MM.

The mean of MM ( $\overline{M M})$ taken by operator 1 and operator 2 was used for further analysis.

The three measurement methods were significantly different $(\mathrm{p}<0.05)$ in eight of the ten "common measurements" with the exception of medial malleolus height $(\mathrm{P}=0.4418)$ and lateral malleolus height $(\mathrm{P}=0.4607)$ (Table 6). The post-hoc SNK tests (Table 6) showed that there were no significant differences between $\overline{M M}$ and SM in five dimensions (foot length, arch length, heel-to-medial malleolus, medial malleolus height and lateral malleolus height). Four dimensions, medial malleolus height, lateral malleolus height, instep girth and short heel girth were not significantly different between $\overline{M M}$ and CP (Table 6). The descriptive statistics of the measuring methods SM, CP and $\overline{M M}$ are summarized in Table 7. As a whole, the training data set results indicated that for all length dimensions, SM was significantly closer to $\overline{M M}$ than was $\mathrm{CP}$, and, on the other hand, for the instep girth and short heel girth dimensions, CP was significantly closer to 
$\overline{M M}$ than SM.

\section{[Insert Table 6 \& Table 7 Here]}

The paired t-test was used to compare the $\mathrm{SM}$ and $\mathrm{MM}$ for the eight "other measurements" (Table 8). SM and $\overline{M M}$ were significantly different $(\mathrm{p}<0.05)$ for five of the eight "other measurements" with the exceptions being the heel to fifth toe length $(\mathrm{p}=0.8328)$, the long heel girth $(\mathrm{p}=0.9135)$ and the waist girth $(\mathrm{p}=0.1723)$.

\section{[Insert Table 8 Here]}

\subsubsection{Linear regression model}

Comparisons between SM and $\overline{M M}$ in the training data set revealed significant differences in ten of the 18 foot dimensions (heel-to-lateral malleolus, foot width, heel width, bimalleolar width, mid-foot width, height at 50\% of the foot length, ball girth, instep girth, short heel girth and ankle girth). Similarly, the comparison between CP and $\overline{M M}$ showed significant differences in six of the ten foot dimensions (Table 6). These results indicate that $\mathrm{SM}$ and $\mathrm{CP}$ are not exactly the same as MM. Hence, a linear regression was used to adjust the discrepancies between SM and MM. The 10 foot 
dimensions that were significantly different between SM and MM were subjected to a linear regression of the form $\mathrm{SM}=\mathrm{a} * \overline{M M}+\mathrm{b}$ (Table 9). The hypothesis that $\mathrm{a}=1$ was checked and it was found that $\mathrm{a}=1$ for all the regression equations at $\mathrm{p}=0.05$. Hence, the regression was re-run in the form of $\mathrm{SM}=\overline{M M}+\mathrm{b}$ (Table 10 and Figure 9). All linear regression equations had relatively high $\mathrm{R}^{2}$ values $(>=0.9032)$, which suggested that the intercept (or systematic error) could be used to adjust SM in order to generate the manual measurement.

\section{[Insert Tables 9, 10 \& Figure 9 Here]}

\subsubsection{Measurement method comparison of the test data set}

The test data set was used to compare SM, CP and MM. The SM measurements of heel-to-lateral malleolus, foot width, heel width, bimalleolar width, mid-foot width, height at $50 \%$ of the foot length, ball girth, instep girth, short heel girth and ankle girth were adjusted using the $\mathrm{SM}=\overline{M M}+\mathrm{b}$ linear regression models (Table 10 ).

ANOVA and post-hoc SNK tests (Table 11) showed that there were no significant differences between the adjusted SM and $\overline{M M}$ in the ten common foot dimensions. Additionally, the paired t-test (Table 12) showed that there were no significant 
differences between adjusted SM and $\overline{M M}$ in 17 of the 18 dimensions, with the only exception being heel width $(\mathrm{P}=0.0123)$. Figure 10 shows the heel width differences between the adjusted SM and $\overline{M M}$ for each participant. The maximum of the absolute difference is less than $2 \mathrm{~mm}$. The descriptive statistics of the differences between the adjusted SM and $\overline{M M}$ for 18 foot measurements are summarized in Table 12. After adjusting SM with the regression equations given in Table 10, the differences with $\overline{M M}$ were within $3 \mathrm{~mm}$ for all the lengths except the heel to fifth toe, within $2 \mathrm{~mm}$ for all widths and within $3.5 \mathrm{~mm}$ for all heights. The ball girth, short heel girth and waist girth measurements showed higher precision (within 5mm) in the adjusted SM.

\section{[Insert Table 11, Table 12 \& Figure 10 Here]}

\section{Discussion}

In this study, foot measurements obtained from three methods were compared. These included manual measurements (MM) using simple measuring devices, commercial software generated measures (CP) and the simulated measurements (SM) obtained from our coded algorithms. The manual measuring sessions consisted of four repetitions (2 operators $\mathrm{x} 2$ trials). The two operators demonstrated measurement reliability (Table 3 ) 
higher than that established by Liu et al (1999), both within and between operators even though very basic measuring instruments like rulers, tapes and setsquares were used (Table 2). It is hypothesized that good control of the alignment procedures and unambiguous definitions are key ingredients in high measurement reliability.

Even though triangulation errors due to the quality of a laser beam can affect measurement accuracy, they have been reported to be on the order of micrometers (Collier and Nurre, 1999). However, the geometry of a laser system can result in errors on the order of millimeters. Thus, differences in CP and SM compared with MM may be attributed to such an effect. Since the same laser scans were used to obtain both the $\mathrm{CP}$ and SM measurements, differences between the two are likely due to other reasons. The ANOVA on the training data set (Table 6) showed that the three methods, CP, MM and SM were different in eight of the ten common measurements. The only exceptions were the medial and lateral malleolus heights, primarily because these two heights were measured or calculated from the anatomical landmarks on the malleolus. This result clearly shows that knowing the exact locations can provide the same measurement no matter which measurement method is used. The post-hoc SNK tests showed significant differences among the three methods. CP had no significant differences with MM on the instep girth and short heel girth dimensions while the SM measurements of these two dimensions were different from the MM dimensions. The 
SM dimensions were programmed to be identical to those of MM, even though the locations at which the measurements were taken could have been different, as shown below, but the same cannot be said about the CP dimensions. The exact definitions in $\mathrm{CP}$ are unknown and hence differences between SM (or MM) and CP are not surprising. Different organizations and researchers use their own sets of standards of measurements that differ from each other. For example, foot length has been measured in many ways. Freedman et al (1946) defined foot length as the length from the heel to the longest toe tip along rectilinear ordinates. Others such as Baba (1975) defined foot length as the distance from the most posteriorly projecting point on the heel (pternion) to the tip of the most anteriorly projecting toe (acropodion, usually the tip of the big or second toe). Pheasant (1988) measured foot length parallel to the long axis of the foot, from the back of the heel to the tip of the longest toe. Physical measurements are highly dependent by the way they are defined and measured. This dilemma highlights the necessity of developing a set of acceptable and meaningful definitions for the measurement of the foot that would be useful to all manufacturers of footwear.

Since the dimension definitions used in $\mathrm{CP}$ are unknown, it is worthwhile to focus primarily on the differences between MM and SM in order to gain an understanding of the underlying differences between scanned data and tape- or ruler-based data. The ANOVA and paired t-test results for the training data set showed no differences 
between MM and SM for foot length, arch length, heel-to-medial malleolus, heel to fifth toe, medial malleolus height, lateral malleolus height, long heel girth and waist girth (Table 6 and Table 8), The similar medial malleolus and lateral malleolus heights has already being discussed. The lack of any difference between the other measures between SM and MM is primarily attributed to the precise identification of the identical end-points of the measurement. The only exception is the long heel girth where variations between $\mathrm{SM}$ and $\mathrm{MM}$ were very large $(\mathrm{SD}=7.03 \mathrm{~mm}, \mathrm{Max}=10.78 \mathrm{~mm}, \mathrm{Min}=$ $-7.99 \mathrm{~mm}$, see table 8 ), primarily due to inconsistent locations between SM and MM. A more detailed analysis of dimension locations on one of the participants illustrates this effect. Figure 11 shows the dimension locations for SM (point P3) using the algorithm and MM (point P3') when using a tape. The differing locations resulted in a (SM-MM) difference of $10.78 \mathrm{~mm}$ for this particular participant.

\section{[Insert Figure 11 Here]}

The measurements that were significantly different between SM and MM in the training data set (Table 6 and Table 8) were height at 50\% of the foot length, ball girth, instep girth, short heel girth, ankle girth, foot width, heel width, bimalleolar width, mid foot width and heel-to-lateral malleolus distance. The differences in the height at $50 \%$ of the foot length can be attributed to two main reasons: skin deformation and a locational 
issue. The manual measurement is almost always lower than SM (Table 8). A post-experiment check on ten plaster castings showed that the mean difference between SM and the manual measurement on the castings was only $1.17 \mathrm{~mm}$, whereas the difference in the experiment reported here was $2.00 \mathrm{~mm}$ for the training data set when the measurements were on real feet. Thus, the difference of $(2-1.17)=0.83 \mathrm{~mm}$ may be attributed to skin deformation as the castings were made of rigid Plaster of Paris. The second potential reason for the difference relates to a locational issue. At exactly $50 \%$ of the foot length, there may not be any point data as the laser scan slices are separated by a $1 \mathrm{~mm}$ thickness. To ensure that there are points for the height calculation, the algorithm considered the point with the maximum height in the region of $[50 \%$ of the foot length- $0.6,50 \%$ of the foot length +0.6 ] (see Section 3.2.3 Height). Since the scan slices are $1 \mathrm{~mm}$ apart, using a total thickness of $1.2 \mathrm{~mm}$ will guarantee that at least one slice is included in the height calculation. This operation will always result in a SM that is larger as the region encompasses points that are $0.6 \mathrm{~mm}$ on either side of the middle of the foot. Tables 7 and 8 show that SM is smaller than MM in ball girth, instep girth, short heel girth, and ankle girth. Two potential reasons for the differences are the use of the convex hull for determining girths and the approximation of using point-to-point linear distances to determine girth. Since a distance of $1 \mathrm{~mm}$ separated the scanned sections, it was necessary to consider a slab when determining girths even with the use of landmarks or control points as the number of points on any inclined 
plane can otherwise be very small. The slab thickness can influence the girth measurement. Figure 12 illustrates two cases where the slab thickness was $1.2 \mathrm{~mm}$ and $7.2 \mathrm{~mm}$. As can be seen from Figure 13, the girth increases monotonically with increasing region thickness due to an increase in the size of the convex hull. In addition, the sum of the Euclidean distances between neighboring points on the 2D convex hull was used to determine the SM girths and such a calculation will not account for the curvatures present in a girth measurement even though a higher number of points can approximate the curvature. The only possible way to get a higher number of points is to increase the thickness of the section, which can cause other artifacts as explained above. Hence, it may be appropriate to investigate the effects of using differing fitting methods such as B-Splines, NURBS, Bezier or Catmull curves (Mortenson, 1939; Su and Liu, 1989) in the modeling. In addition, computational integration along a curve rather than the sum of piecewise linear distances may allow a higher accuracy in the girth computation (Priestley, 1997). Additionally, other approaches that can be used include the generation of a closed convex surface (Hagen and Roller, 1991) followed by the determination of a geodesic distance (Kimmel and Sethian, 1998) between the chosen points.

[Insert Figures 12 and 13 Here] 
It is clear that there are differences between $\mathrm{SM}$ and $\mathrm{MM}$ in ten of the dimensions. To understand if these errors are systematic, a linear regression was performed to convert the SM measurements to MM. Table 10 shows that the regression of the form $\mathrm{SM}=\overline{M M}+\mathrm{b}$ (constant) can achieve $\mathrm{R}^{2}>0.9$ for the 10 dimensions that were found to be significantly different. The form of the equation with a constant is an indication that the difference is primarily the result of a systematic bias induced from either the manual measurements or the algorithms. To unify and check the influence of the systematic error, the SM(Adjusted) was calculated as (SM-b) on the test data set. The ANOVA on the test data set (Table 11) indicated differences among MM, CP and SM(Adjusted) for seven of the ten dimensions with the exceptions of the medial and lateral malleolus height and the instep girth dimensions. The post-hoc SNK tests (Table 11) and the paired t-tests (Table 12) showed no difference between MM and SM(Adjusted) except for heel width. The difference in heel width can be traced to a point construction issue in the scanner software. In the rearfoot region, the scanner captures the lower leg as well. In order to generate a smooth shape for each slice, the software seems to use a construction center. If the captured height is large (like in the rearfoot region), the radius of the construction line will tend to be large and vice versa. This effect is clearly seen when we changed the height of the scan in the rearfoot region and obtained point cloud data for participant number 5 and as shown in Figure 14. The inset of Figure 14 shows how the point data moves inward at the maximum width 
location as the scanned height increases. The variation in width with the change in height is shown for two participants in Figure 15. For participant number 5, the heel width reduced from $61.43 \mathrm{~mm}$ to $59.60 \mathrm{~mm}$ when the scanning height was changed from $25 \mathrm{~mm}$ to $150 \mathrm{~mm}$. The scan height that was used for SM was $130 \mathrm{~mm}$ and it is clear from Figure 15 that it is not optimal. However, the cause for the difference between SM and MM was only found after the fact and prior to that it seemed reasonable to use the highest height that the scanner could possibly scan in order to generate the point cloud. Lowering the scan height can have adverse effects on the SM measurement of malleolus heights, bimalleolar width, short heel girth and ankle girth and hence a compromise is needed. Thus, if heel width is not a critical measure, it may be appropriate to increase the scanning height in the rearfoot region to generate accurate measures for these four dimensions. Another alternative method is to use differing scanning heights for different dimensions. A low height (e.g. $25 \mathrm{~mm}$ ) can be used for the measurement of heel width whereas all other measurements can be obtained with a higher scanning height such as $130 \mathrm{~mm}$. Such a procedure, however, may be unique to each type of scanner.

\section{[Insert Figures 14 and 15 Here]}

\section{Conclusions}


In general, this study highlights important differences in manual foot measurements and 3D scanned measurements. For both cases, it is of utmost importance to have good definitions and registration procedures so that the measurements can be reproducible and repeatable. The differences between the commercial software measures and those that we generated may be primarily attributed to differences in definitions and the alignment procedures. The registration process can make a significant difference in measurements of linear as well as girth dimensions. Because manual measurements may take a longer time compared with scanning, there is a possibility of shape changes due to the participant fatigue (Goonetilleke, 1999; Winkel and Jørgensen, 1986). In addition, the skill level of the measurer and the instruments used can influence the measurements, even though having well-defined measurement procedures can minimize this effect as seen in our experimental results. Similarly, the scanned data may not be free of errors. The presence of dust particles on the scanner bed or its side walls or high levels of ambient light can cause the divergence of the laser beam and thereby affect the noise introduced and the accuracy of the scanned points data (Blais et al., 2000; Bornaz et al., 2005). In addition, transformations of data into a single global coordinate system, data stitching and the creation of a computer model can result in inaccuracies as well. Thus, it is essential that the measurement algorithms be robust in order to be insensitive to any noise in the point cloud data. Using the mean of many points (such as the mean 
of five points as in this study) rather than just one point can prevent or minimize the effect of noisy data. In addition, locating some of the critical points that have to be measured is not as easy when using algorithms in comparison with locating the point manually as palpation is not possible. The lack of a difference in the malleolus heights among the three methods is proof that the problem can be minimized, if not eliminated, by placing landmarks after manual location or palpation. It is also important to understand the point cloud construction methodology in the scanned data, as it can affect some measurements such as heel width. Overall, choosing the method to use for taking measurements on feet will depend on many different factors. It is important to note that any measurement is dependent on the registration, dimension definition, and algorithm used. The ultimate method selection should be based on cost, accuracy, and precision of the method or algorithms and the allowable tolerances for each measurement.

\section{Acknowledgment}

The authors would like to thank the Research Grants Council of Hong Kong for funding this study under grant HKUST 6162/02E.

\section{References:}

Baba, K., 1975. Foot measurement for shoe construction with reference to the relationship between foot length, foot breadth, and ball girth. Journal of Human 


\section{Ergology, 3: 149-156}

Bartlett, M. S., 1937. Properties of sufficiency and statistical tests. Proceedings of the Royal Society of London, Series A 160 268-282.

Berg, M. D., Kreveld, M, V., Overmars, M., and Schwarzkopf, O., 1997. Computational geometry: algorithms and applications. Springer: Berlin; Heidelberg.

Blais, F., Bisson, J. A., Williams, S., Robertson, N., Rozin, S., and Nelson, A., 2000. The shape grabber footscanner: A low cost high accuracy 3-D system for the acquisition of human feet. In: Three-Dimensional Image Capture and Applications III (Eds: B. D. Corner and J. H. Nurre), Proceedings of the SPIE Vol 3958.: 178-186.

Bornaz, L., Lingua, A., and Rinaudo, F., 2005. Engineering and environmental applications of laser scanner techniques. Politecnico di Torino- Dipartimento di Georisorse e Territorio, C, So Duca degli Abruzzi, Torino, Italy.

Brannock, 2005. http://www.brannock.com/. Jan 182006.

Bunch R.P., 1988. Foot Measurement Strategies for Fitting Athletes, Journal of Testing and Evaluation, 16 (4): 407-411.

Carocci, M., Lazzari, S., Rodella, R., and Sansoni, G.,. 1997. 3D range optical sensor: Analysis of the measurement errors and development of procedures for their compensation. Proceedings of three-dimensional image capture and applications, SPIE 3313, San Jose, CA.: 178-188.

Collier, J. and Nurre, J. H., 1999. Examining laser triangulation system performance using a software simulation. In: Proceedings of Three-dimensional Image capture and applications II (IS\&T/SPIE) conference. San Jose, California, January 1999, SPIE Vol 3640: 76-85.

Clarks, Ltd. Training Dept., 1976. Manual of shoemaking, 2nd edition, Training Department Clarks. 
Corner, B. and Hu. A., 1997. Proceedings Three-dimensional image capture and applications, SPIE 3313, San Jose, CA.: 90-99.

Freedman A, Huntington EC, Davis GC, Magee RB, Milstead VM, and Kirkpatrick CM., 1946. Foot dimensions of soldiers. Third partial report project NT-13. Fort Knox: Armored Medical Research Laboratory.

Gärtner, H., Lavoie, J.F., Vermette, E., Houle, P. S., 1999. Multiple structured light system for the 3D-measurement of feet. In: Proceedings of Three-dimensional Image capture and applications II (IS\&T/SPIE) conference. San Jose, California, January 1999, SPIE Vol 3640: 104-114.

Goonetilleke, R. S., 1999. Footwear Cushioning: Relating Objective and Subjective Measurements. Human Factors. 41(2): 241-256.

Hawes, M.R. and Sovak, D., 1994. Quantitative morphology of the human foot in a north American population, Ergonomics, 37(7): 1213-1226.

Hagen, H and Roller, D., 1991. Geometric modeling: methods and applications. Springer: Verlag; Berlin; Heidelberg.

Houle, P.S., Beaulieu, E., Liu, Z., 1997. Novel fully integrated computer system for custom footwear: From 3D digitization to manufacturing. Proceedings Three-dimensional image capture and applications, SPIE 3313, San Jose, CA.: $65-73$.

Kimmel, R. and Sethian, J. A., 1998. Computing geodesic paths on manifolds, Proceedings of National Academy of Sciences, 95(15): 8431-8435.

Kouchi M., 2003. Inter-generation differences in foot morphology: Aging or secular change? Journal of Human Ergology, 32: 23-48.

Liu W., Miller J., Stefanyshyn D., and Nigg B. M., 1999. Accuracy and reliability of a technique for quantifying foot shape, dimensions and structural characteristics. Ergonomics, 42 (2): 346-358. 
Luximon, A., and Goonetilleke, R. S., 2004. Foot Shape Modeling. Human Factors, 46(2), 304-315.

Montgomery, D. C., 2001. Design and analysis of experiments. $5^{\text {th }}$ Edition. 624 627. John Wiley \& Sons, Inc. NJ: USA.

Mortenson, M. E., 1939. Geometric modeling. John Wiley \& Sons, New York; Chichester; Brisbane; Toronto; Singapore.

Pheasant S., 1988. Bodyspace: Anthropometry, Ergonomics and Design, Taylor \& Francis. New York. Philadelphia. London.

Pivečka J., and Laure S., 1995. Practical handbook for shoe designers: The shoe last. International school of modern shoemaking.

Priestley, H. A., 1997. Introduction to Integration. Oxford University Press Inc. New York.

Rossi, W.A., 1983. The high incidence of mismated feet in population, Foot and Ankle, 4: $105-112$.

Shrout P. E., and Fleiss J. L., 1979. Intraclass correlations: use in assessing operator reliability. Psychological bulletin. 86(2): 420-428.

Su, B. Q., and Liu, D. Y., 1989. Computational geometry : curve and surface modeling. Academic Press, Inc.,Boston.

Venkatappaiah B., 1997. Introduction to the Modern Footwear Technology, Footwear Science and Engineering (Rtd) Central Leather Research Institute, Chennai.

Viavor, 2005. Shoe fitting viavor technology, Viavor, Retrieved 29 September 2005, from http://www.viavor.com/en/fitting/technology.php.

Vorum Research Corporation 2000, User Manual of Canfit-Plus ${ }^{\mathrm{TM}}$ Yeti $^{\mathrm{TM}}$ Foot Scanner, Canada.

Webster, K. E., Wittwer, J. E., and Feller, J. A., 2005. Validity of the GAITRite ${ }^{\circledR}$ walkway system for the measurement of averaged and individual step parameters 
of gait. Gait \& Posture. 22: 317-321.

Wehr, A., 1999. 3-Imaging laser scanner for close range metrology. In: Proceedings of the SPIE Conference on Laser radar technology and applicartions IV, Orlando, Florida April 1999. SPIE Vol 3707: 381-389.

White R. M., 1982. Comparative anthropometry of the foot, (Tech. Report IPL-230) U.S. Army Natick Research \& Development Laboratories, Natick, Massachussetts.

Winkel J. and Jørgensen K., 1986. Swelling of the foot, its vascular volume and systemic hemoconcentration during long-term constrained sitting, European Journal of Applied Physiology, 55 (2): 162-166. 


\section{$\underline{\text { Lists of figures }}$}

Figure 1. Foot dimensions

Figure 2. Foot alignment on measuring device. Left figure shows the template used for aligning foot.

Figure 3. Landmarks on foot surface

Figure 4. Foot alignment. The black points in left and right figures are before alignment, while the gray colored points are after alignment. The dotted curve at the back of the foot on the left is the fitted $2^{\text {nd }}$ degree polynomial, while the circle on the dotted curve is the pternion. The distance from the $1^{\text {st }}$ landmark to the line parallel to the $\mathrm{X}$-axis across pternion has been transformed from $14.6 \mathrm{~mm}$ to $38.1 \mathrm{~mm}$ with the registration procedure.

Figure 5. (a) Region considered for Heel to $5^{\text {th }}$ toe length determination as shown in (b).

Figure 6. (a) Transformations to calculate instep girth (b) Fitted 2D convex hull corresponding to ankle girth.

Figure 7. Girths and their locations

Figure 8. Location of control points

Figure 9. Linear regression $(\mathrm{Y}=\mathrm{X}+\mathrm{b})$ between $\mathrm{SM}$ and mean of $4 \mathrm{MMs}(\overline{M M})$ for ball girth of training data set $(\mathrm{N}=10)$

Figure 10. Differences (adjusted SM- $\overline{M M})$ in heel width for the test data set $(\mathrm{N}=10)$

Figure 11. Inconsistent measuring locations between SM (Point P3) and MM (Point P3') when determining long heel girth of participant No. 1 of training data set.

Figure 12. Variation in convex hull shape for the short heel girth calculation of participant No. 8 of test data set with varying tolerance.

Figure 13. Variation of SM short heel girth with tolerance value and corresponding MM value for participant No. 8 of test data set. 
Figure 14. Foot shape construction lines for differing scan heights on plane of heel width measurement for participant No. 5 of test data set. Heel width is measured as the maximum width. Point "a" represents the heel width measuring location for a scan height of $25 \mathrm{~mm}$ and point " $b$ " represents the location for height $150 \mathrm{~mm}$ in the zoomed view

Figure 15. SM heel widths measured at different scan heights (Participant No.5 and Participant No. 10 of test data set) 


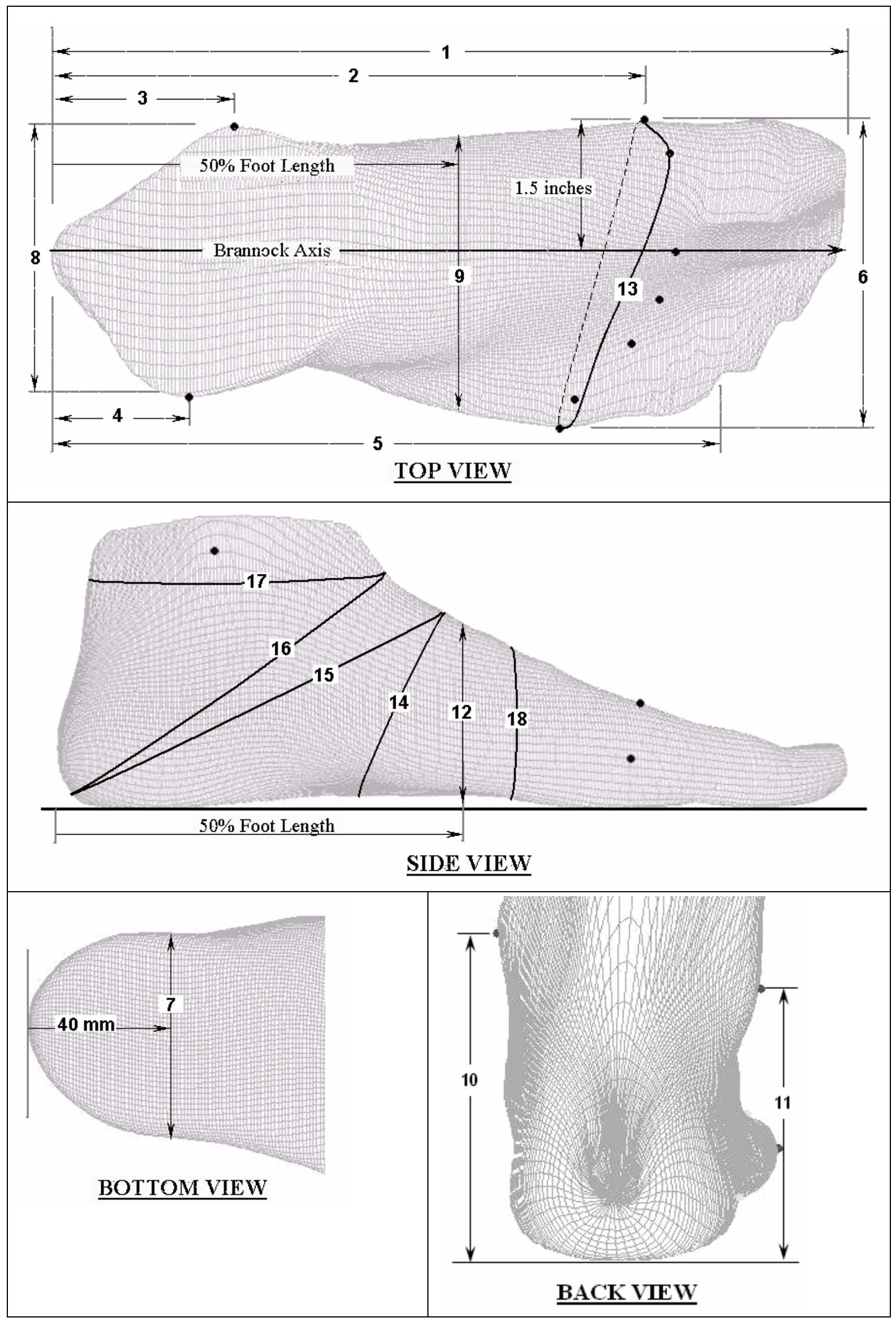

Figure 1. Foot dimensions 


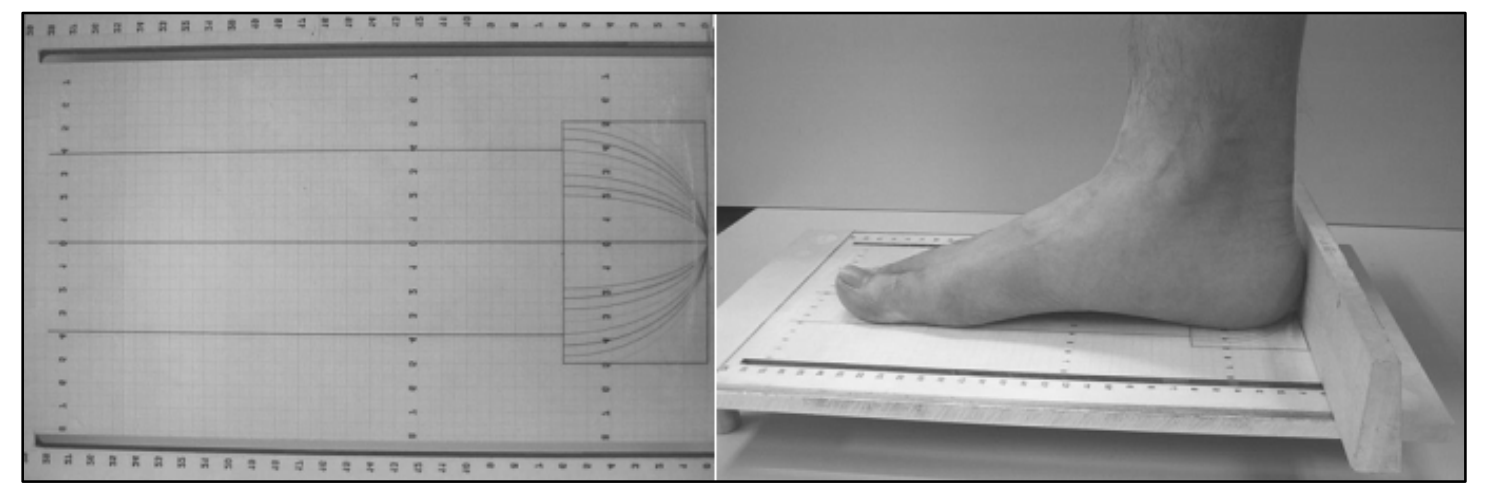

Figure 2. Foot alignment on measuring device. Left figure shows the template used for aligning foot. 


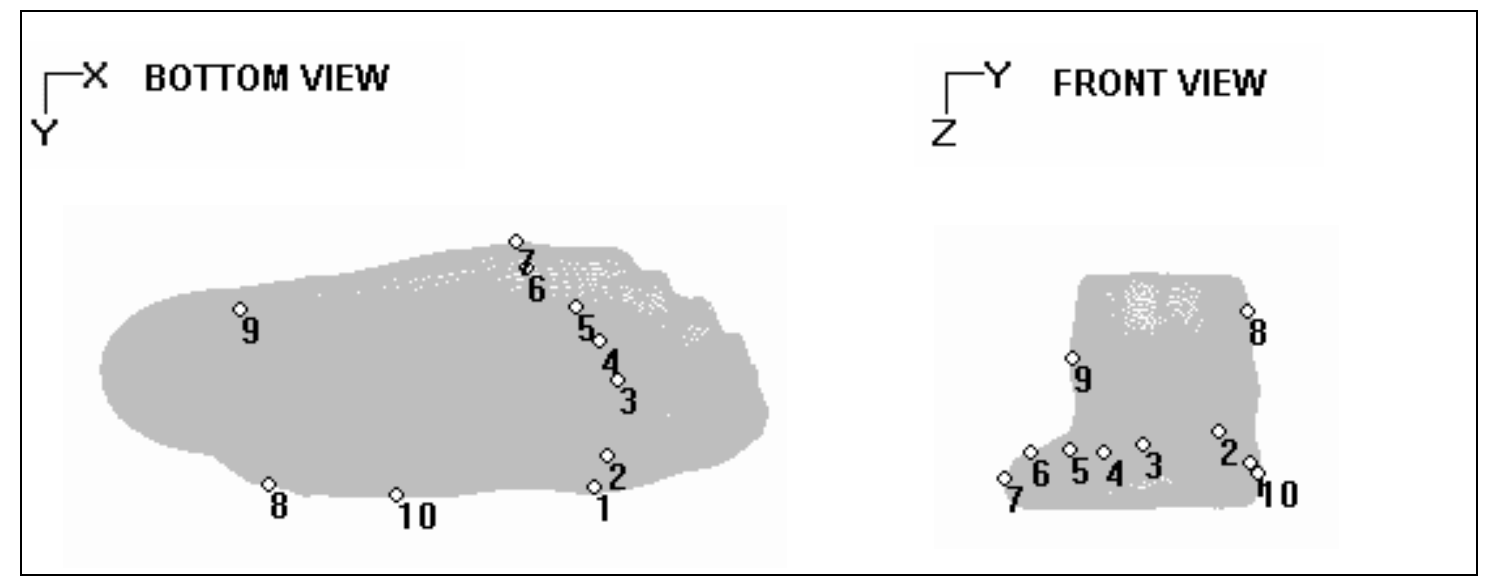

Figure 3. Landmarks on foot surface 


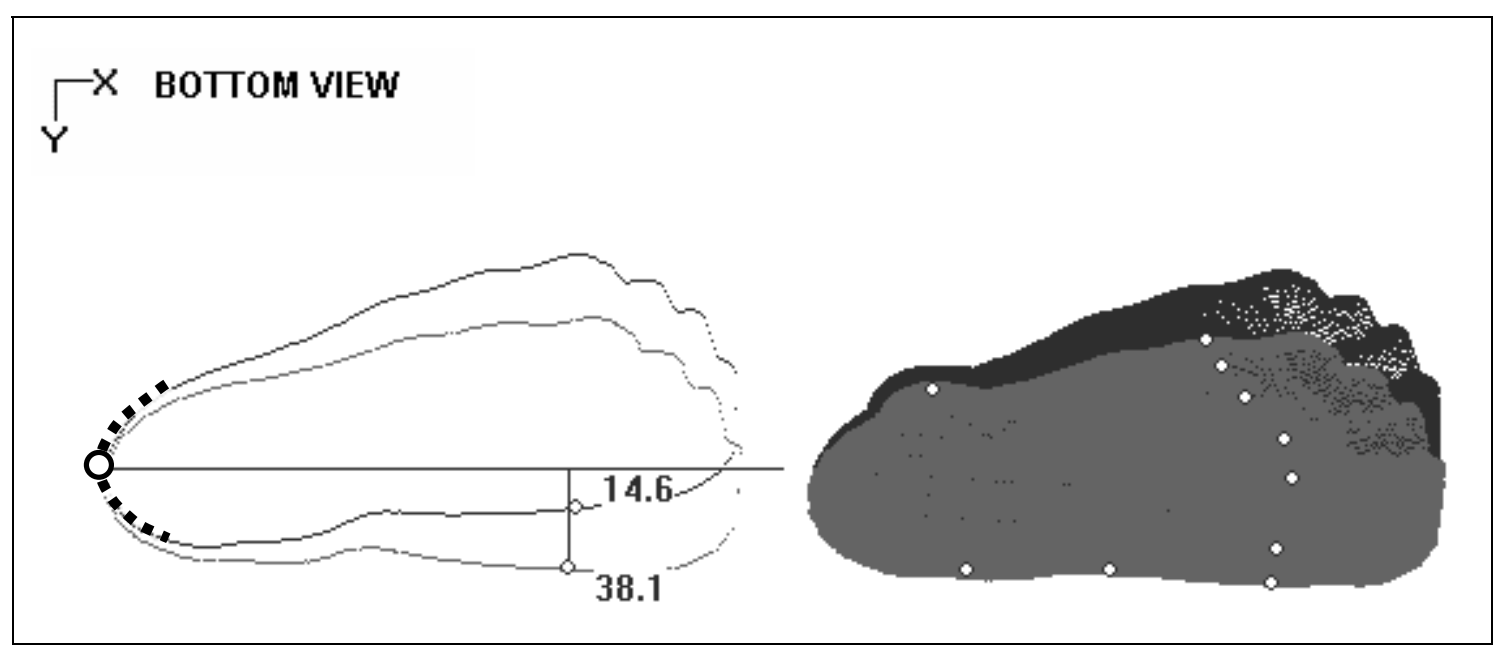

Figure 4. Foot alignment. The black points in left and right figures are before alignment, while the gray colored points are after alignment. The dotted curve at the back of the foot on the left is the fitted $2^{\text {nd }}$ degree polynomial, while the circle on the dotted curve is the pternion. The distance from the $1^{\text {st }}$ landmark to the line parallel to the $\mathrm{X}$-axis across pternion has been transformed from $14.6 \mathrm{~mm}$ to $38.1 \mathrm{~mm}$ with the registration procedure. 


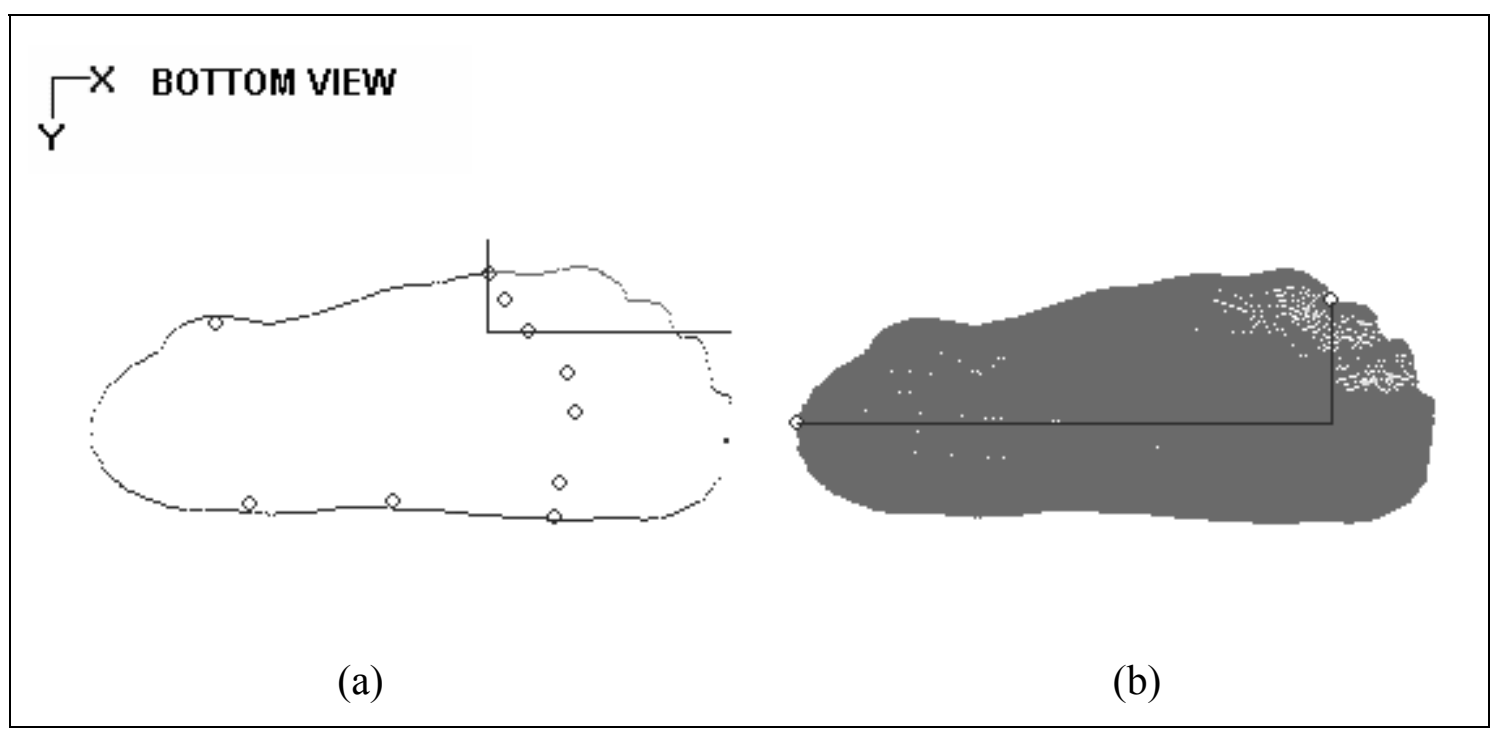

Figure 5. (a) Region considered for Heel to $5^{\text {th }}$ toe length determination as shown in (b). 


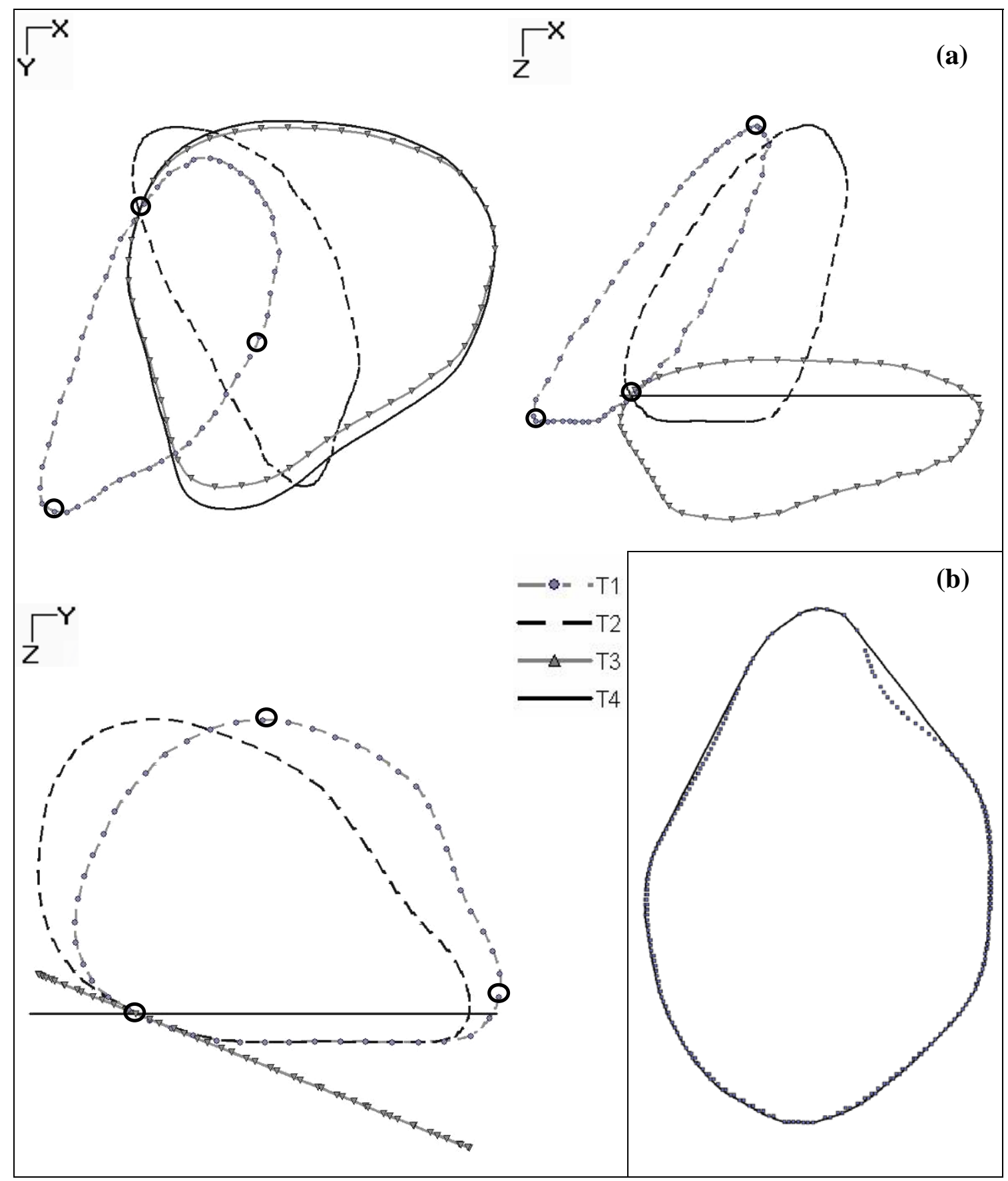

Figure 6. (a) Transformations to calculate instep girth (b) Fitted 2D convex hull corresponding to ankle girth 


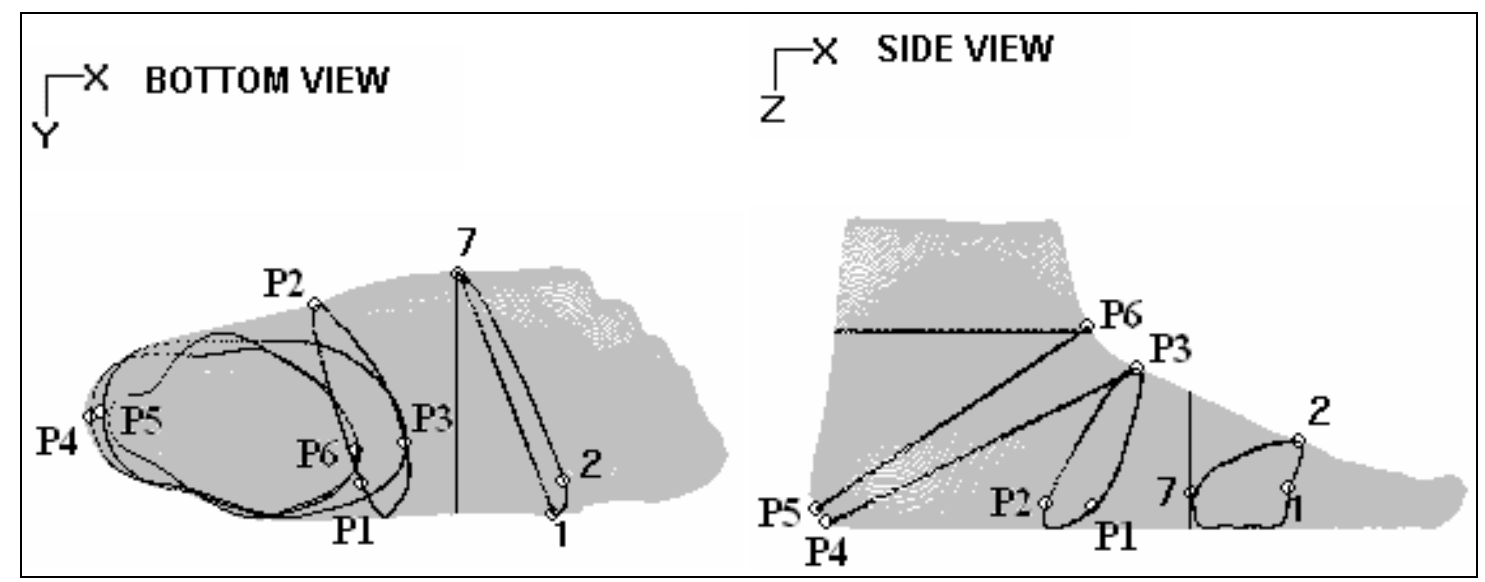

Figure 7. Girths and their locations 


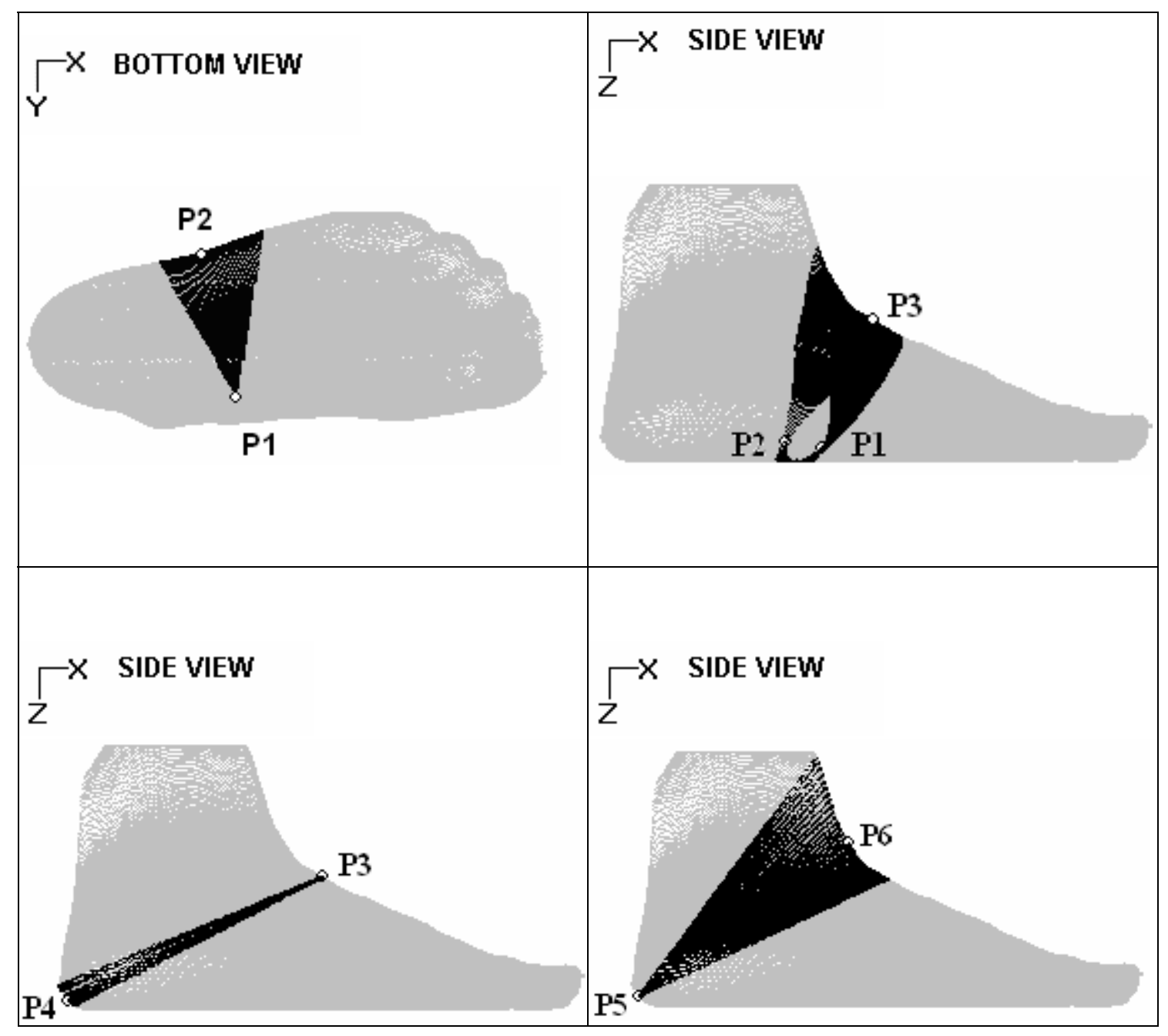

Figure 8. Location of control points 


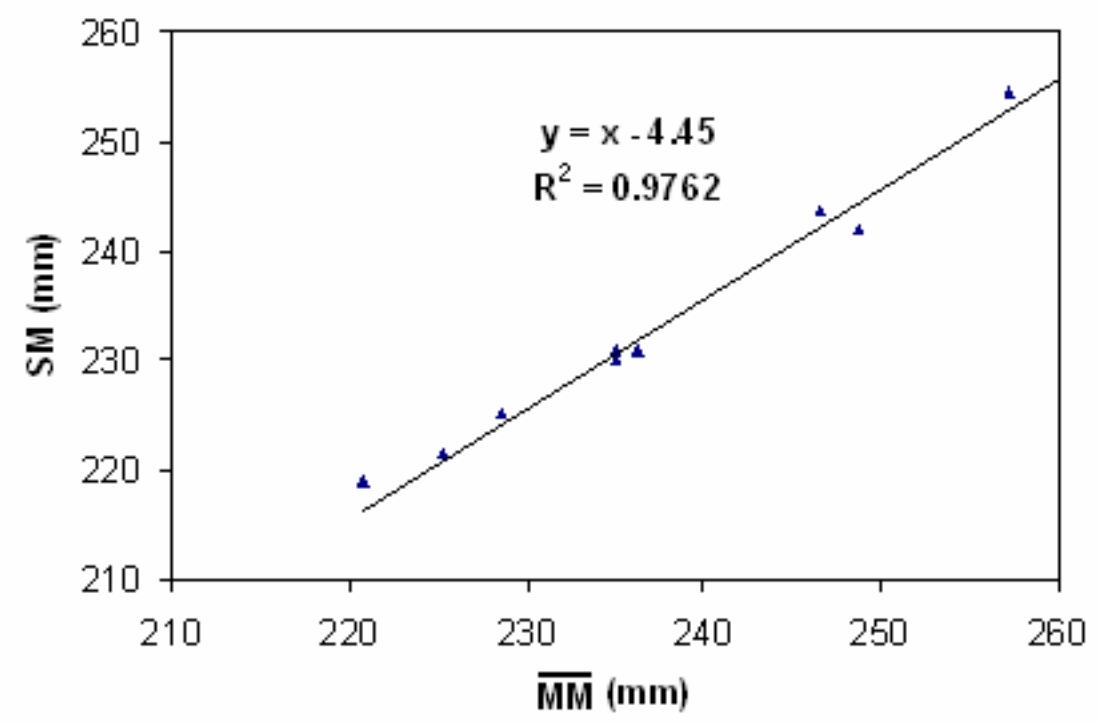

Figure 9. Linear regression $(\mathrm{Y}=\mathrm{X}+\mathrm{b})$ between $\mathrm{SM}$ and mean of $4 \mathrm{MMs}(\overline{M M})$ for ball girth of training data set $(\mathrm{N}=10)$ 


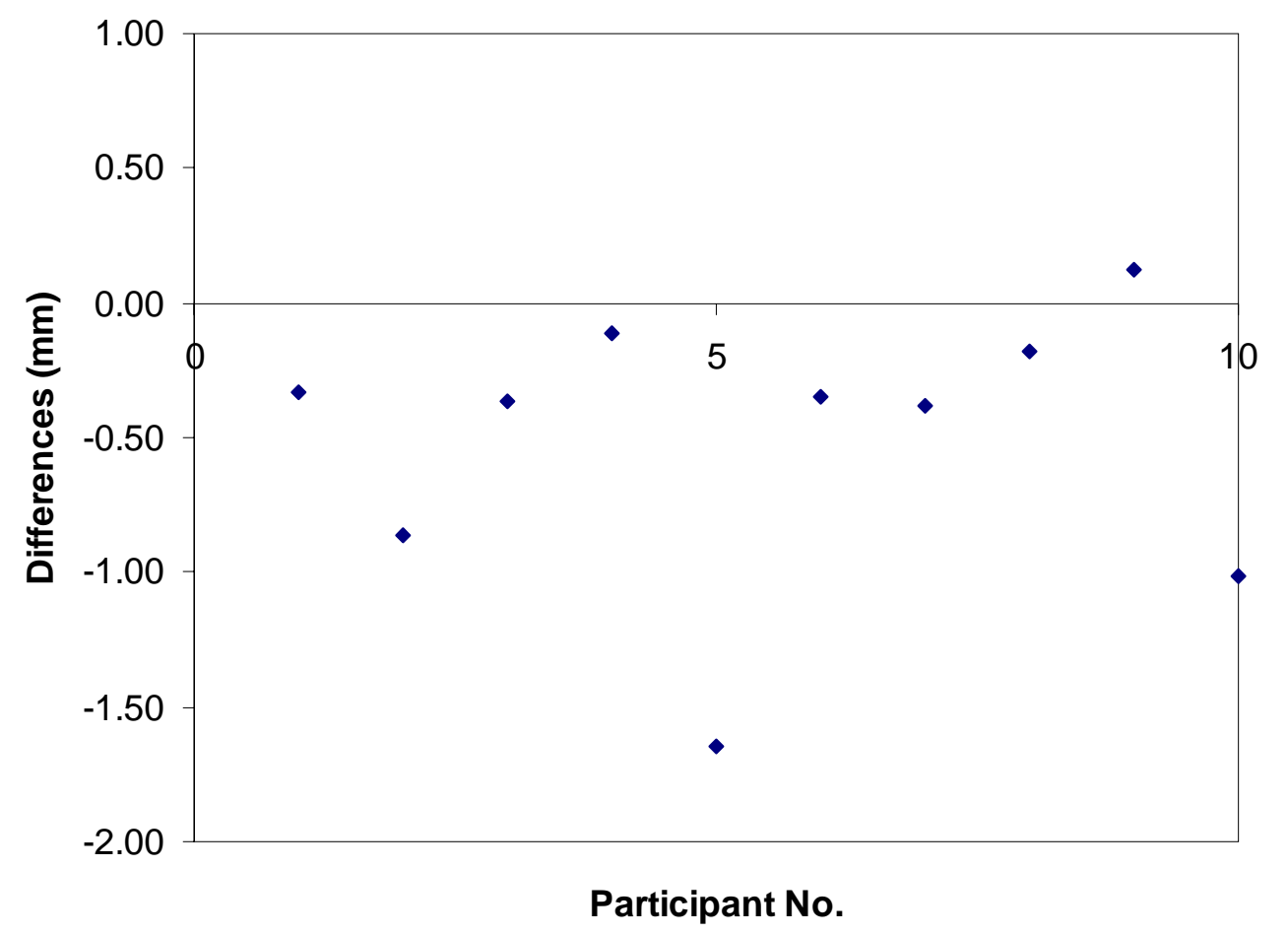

Figure 10. Differences (adjusted SM- $\overline{M M}$ ) in heel width for the test data set $(\mathrm{N}=10)$ 


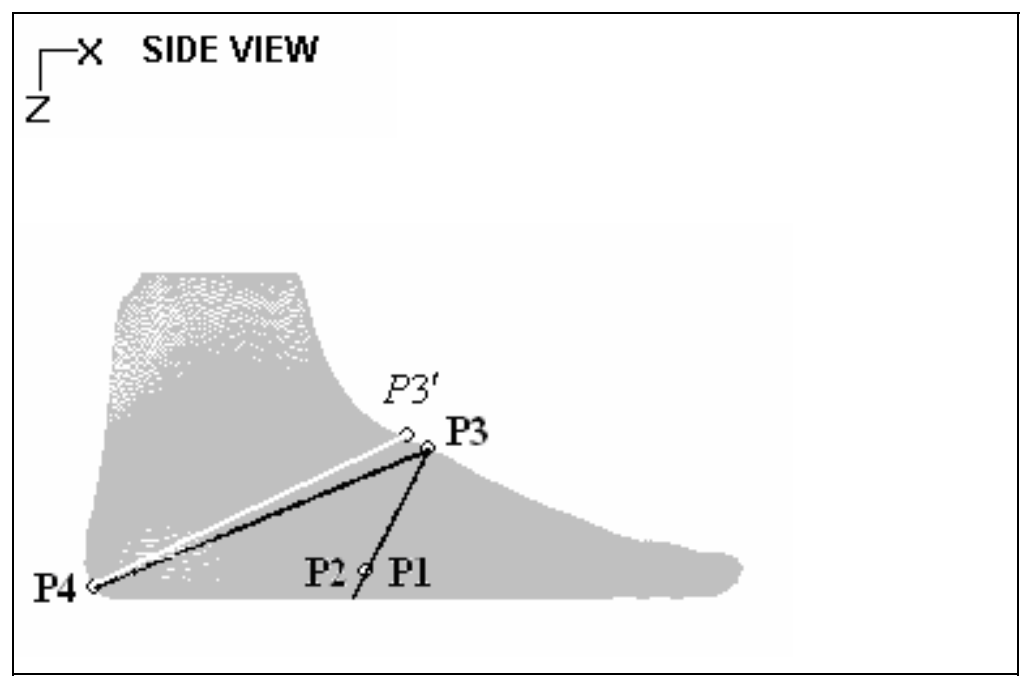

Figure 11. Inconsistent measuring locations between SM (Point P3) and MM (Point P3') when determining long heel girth of participant No. 1 in training data set. 


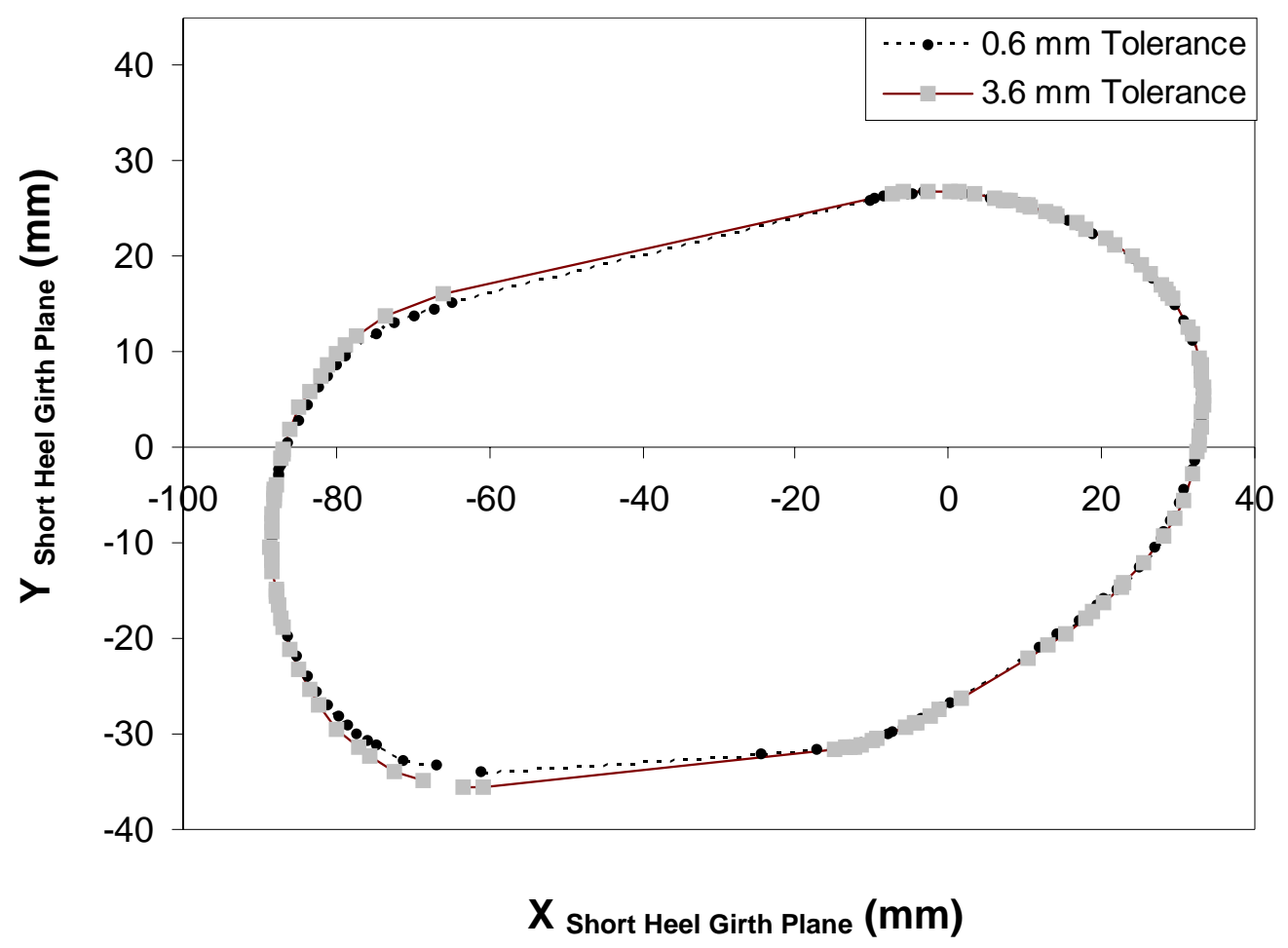

Figure 12. Variation in convex hull shape for the short heel girth calculation of participant No. 8 of test data set with varying tolerance. 


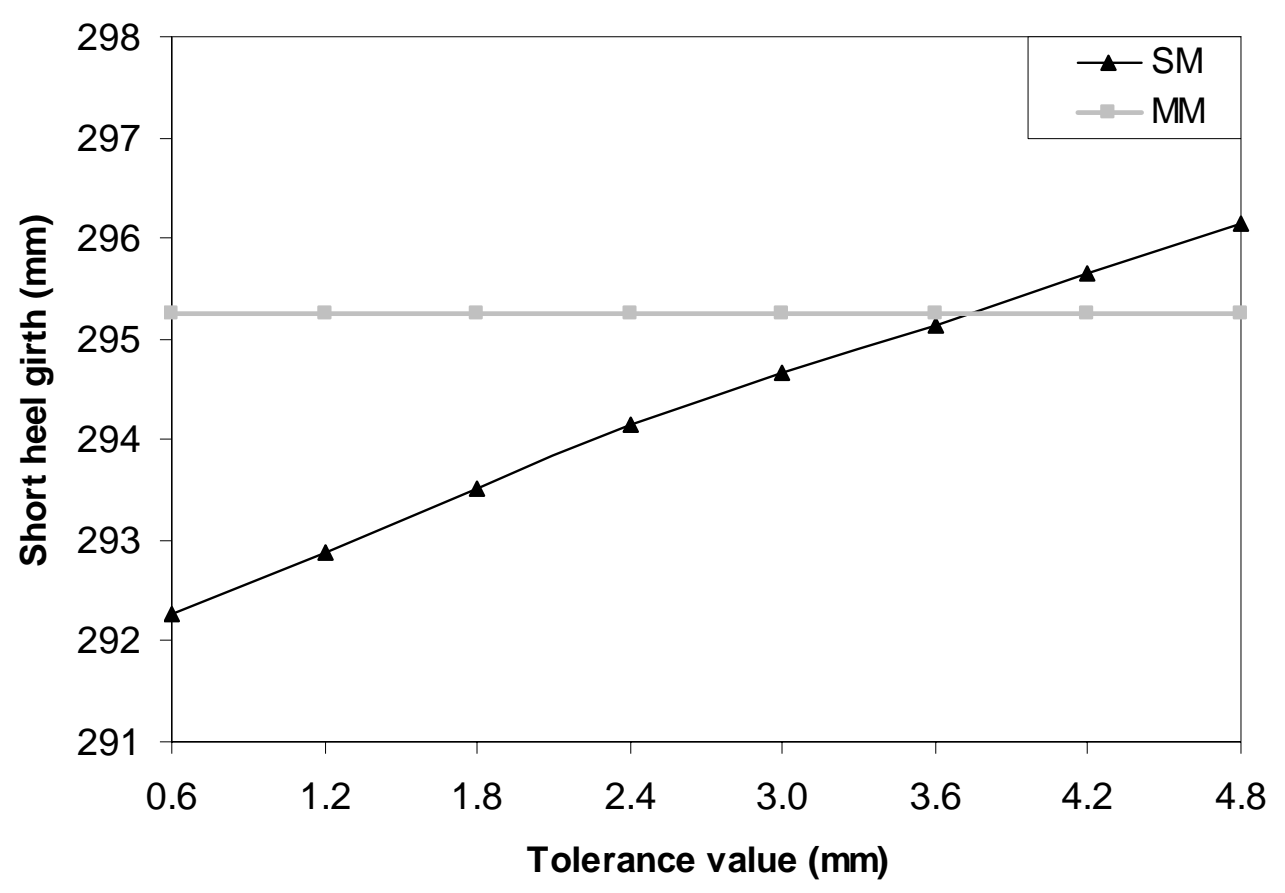

Figure 13. Variation of SM short heel girth with tolerance value and corresponding MM value for participant No. 8 of test data set. 


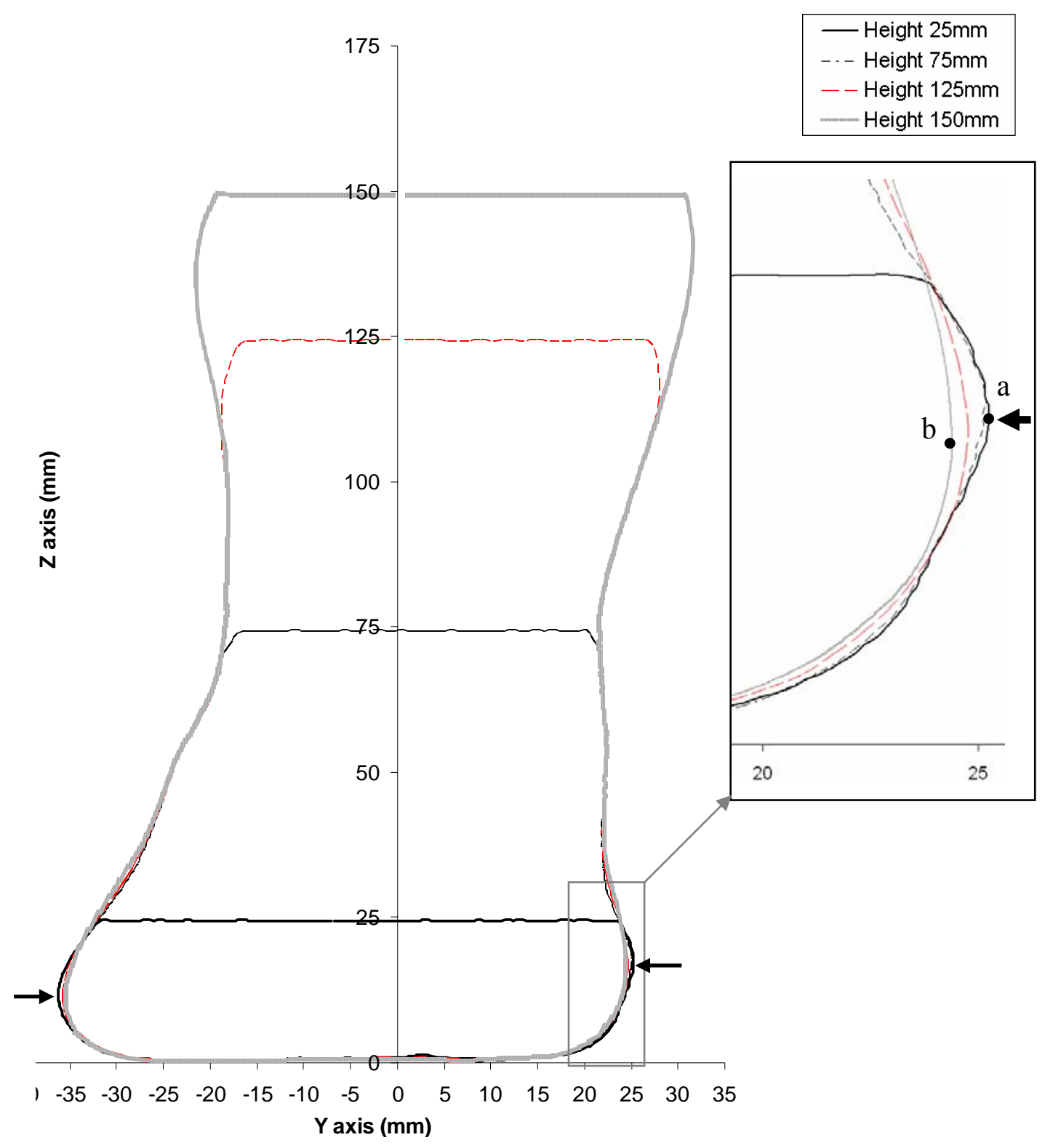

Figure 14. Foot shape construction lines for differing scan heights on plane of heel width measurement for participant No. 5 of test data set. Heel width is measured as the maximum width. Point "a" represents the heel width measuring location for a scan height of $25 \mathrm{~mm}$ and point " $\mathrm{b}$ " represents the location for height $150 \mathrm{~mm}$ in the zoomed view 


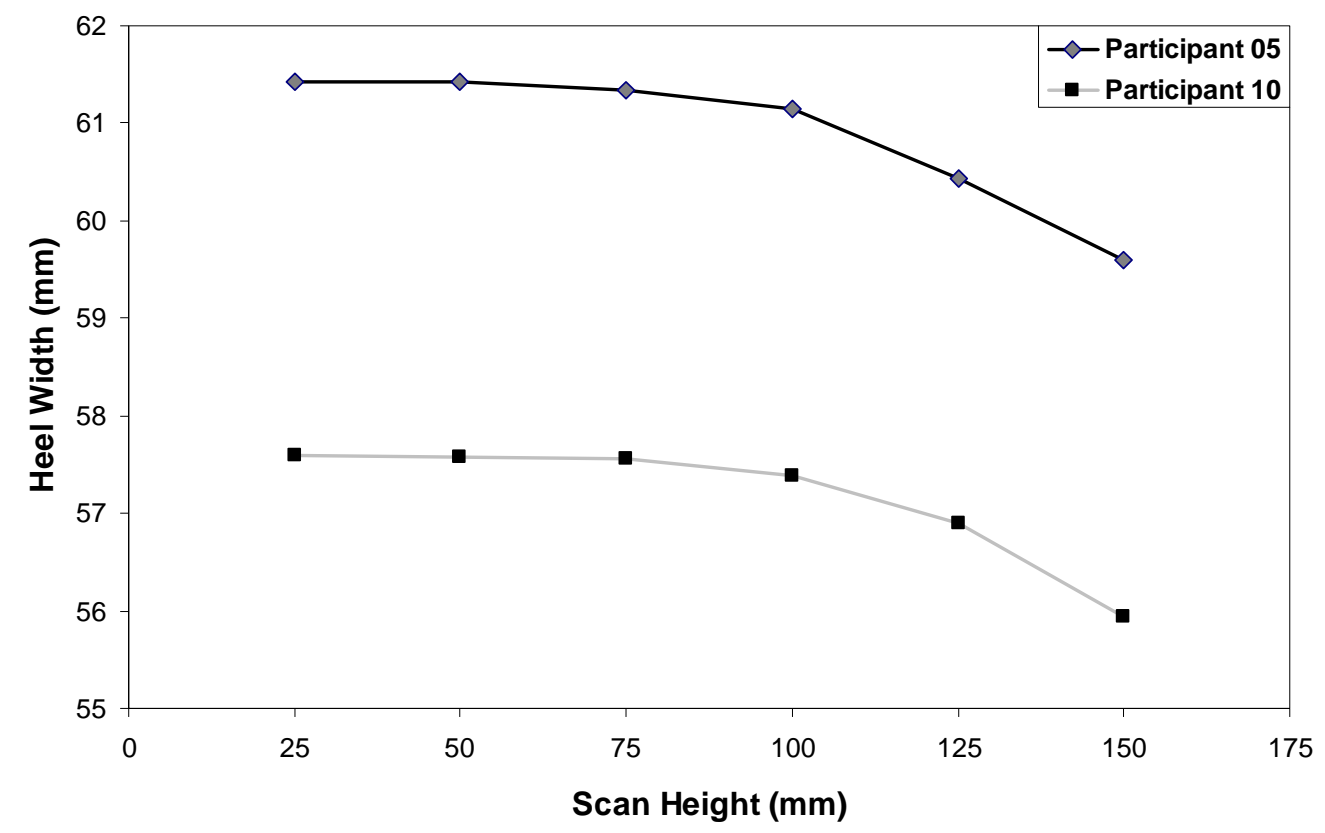

Figure 15. SM heel widths measured at different scan heights (Participant No.5 and Participant No. 10 of test data set) 


\section{List of Tables}

Table 1. Descriptive statistics of participants $(\mathrm{N}=20)$

Table 2. Foot dimension definitions. Numbers correspond to those shown in Figure 1.

Table 3. Inter-operator and intra-operator reliabilities: intraclass correlation coefficients (ICCs)

Table 4. Descriptive statistics of all 18 measurements obtained from the three methods, MM, SM and CP for the Training data set $(\mathrm{N}=10)$. All measurements in $\mathrm{mm}$.

Table 5. Descriptive statistics of all 18 measurements obtained from the three methods, MM, SM and CP for the Test data set $(\mathrm{N}=10)$. All measurements in $\mathrm{mm}$.

Table 6. ANOVA and post-hoc Student-Newman-Keuls (SNK) tests for comparing three measuring methods $(\overline{M M}, \mathrm{SM}, \mathrm{CP})$ on 10 common foot measurements of training data set

Table 7. Differences between computerized measurement (SM, CP) and manual measurement $(\overline{M M})$ of the 10 common measurements in training data set

Table 8. Paired t-test results of differences $(\mathrm{SM}-\overline{M M})$ of the 8 other measurements in training data set.

Table 9. Linear regression $\mathrm{SM}=\mathrm{a}^{*} \overline{M M}+\mathrm{b}$ and the hypothesis test of $\mathrm{a}=1$ for measurements that had significant differences between SM and $\overline{M M} \S$ in the training data set. (all measurements in $\mathrm{mm}$ )

Table 10. Linear regression $\mathrm{SM}=\overline{M M}+\mathrm{b}$ for those measurements that had significant differences between SM, $\overline{M M}$ of training data set (all measurements in mm) 
Table 11.ANOVA and post-hoc Student-Newman-Keuls (SNK) tests for comparing the three measurement methods $\left(\overline{M M}\right.$, adjusted $\left.\mathrm{SM}^{\ddagger}, \mathrm{CP}\right)$ on 10 common measurements of test data set

Table 12.Paired t-test results of difference (adjusted $\mathrm{SM}^{\ddagger}-\overline{M M}$ ) on all 18 foot measurements of test data set 
Table 1. Descriptive statistics of participants $(\mathrm{N}=20)$

\begin{tabular}{lcccc}
\hline Characteristics & Mean & Maximum & Minimum & Standard deviation \\
\hline Age (years) & 21.25 & 23 & 19 & 1.16 \\
Height $(\mathrm{cm})$ & 166.0 & 178.0 & 155.3 & 7.44 \\
Body Weight $(\mathrm{kg})$ & 58.26 & 94.25 & 41.80 & 13.36 \\
\hline
\end{tabular}


Table 2. Foot dimension definitions. Numbers correspond to those shown in Figure 1.

[1] Foot length: The distance along the brannock axis (X-direction) from pternion to the tip of the longest toe.

[2] Arch length: The distance along the brannock axis from pternion to the most medially prominent point on the $1^{\text {st }}$ metatarsal head.

[3] Heel to medial malleolus: Length from pternion to the most

Lengths medially protruding point of the Medial Malleolus measured along the brannock axis. (Modified from Kouchi, 2003)

[4] Heel to lateral malleolus: Length from pternion to the most laterally protruding point of the Lateral Malleolus measured along the brannock axis. (Modified from Kouchi, 2003)

[5] Heel to $5^{\text {th }}$ toe: The distance along the brannock axis from pternion to the anterior 5 th toe tip.

[6] Foot width: Maximum horizontal breadth (Y-direction), across the foot perpendicular to the brannock axis in the region in front of the most laterally prominent point on the $5^{\text {th }}$ metatarsal head

[7] Heel width: Breadth of the heel $40 \mathrm{~mm}$ forward of the pternion (Modified from last measurements given in Pivečka and Laure, 1995).

Widths [8] Bimalleolar width: Distance between the most medially protruding point on the medial malleolus and the most laterally protruding point on the lateral malleolus measured along a line perpendicular to the brannock axis (Kouchi, 2003).

[9] Mid-foot width: Maximum horizontal breadth, across the foot perpendicular to the brannock axis at $50 \%$ of foot length from the pternion.

[10] Medial malleolus height: Vertical (Z-direction) distance from the floor to the most prominent point on the medial malleolus

Heights

[11] Lateral malleolus height: Vertical (Z-direction) distance from the floor to the most prominent point on the lateral malleolus

[12] Height at $50 \%$ foot length: Maximum height of the vertical cross-section at $50 \%$ of foot length from the pternion. (Kouchi, 2003)

[13] Ball girth: Circumference of foot, measured with a tape touching

Girths the medial margin of the head of the $1^{\text {st }}$ metatarsal bone, top of the $1^{\text {st }}$ metatarsal bone and the lateral margin of the head of the $5^{\text {th }}$ metatarsal bone 
[14] Instep girth: Smallest girth over middle cuneiform prominence (Clarks, 1976)

[15] Long heel girth: The girth from instep point around back heel point. (Chen, 1993; Clarks, 1976)

[16] Short heel girth: Minimum girth around back heel point and dorsal foot surface (Chen, 1993)

[17] Ankle girth: Horizontal girth at the foot and leg intersection

[18] Waist girth: Circumference at the approximate center of the metatarsal, measured in a vertical plane, perpendicular to the brannock axis. 
Table 3. Inter-operator and intra-operator reliabilities: intraclass correlation coefficients (ICCs)

\begin{tabular}{|c|c|c|c|}
\hline \multirow{2}{*}{ Foot Measurements } & \multirow{2}{*}{$\begin{array}{l}\text { Inter-operator } \\
\text { reliability }^{b} \\
\operatorname{ICC}(2,1)^{a}\end{array}$} & \multicolumn{2}{|c|}{$\begin{array}{c}\text { Intra-operator reliability }^{\mathrm{c}} \\
\operatorname{ICC}(2,1)\end{array}$} \\
\hline & & Operator 1 & Operator 2 \\
\hline \multicolumn{4}{|l|}{ Lengths } \\
\hline Foot length & 1.000 & 0.998 & 0.997 \\
\hline Arch length & 0.994 & 0.994 & 0.986 \\
\hline Heel to medial malleolus & 0.978 & 0.976 & 0.966 \\
\hline Heel to lateral malleolus & 0.920 & 0.841 & 0.943 \\
\hline Heel to $5^{\text {th }}$ toe & 0.999 & 0.995 & 0.998 \\
\hline \multicolumn{4}{|l|}{ Widths } \\
\hline Foot width & 0.988 & 0.992 & 0.978 \\
\hline Heel width & 0.992 & 0.975 & 0.992 \\
\hline Bimalleolar width & 0.978 & 0.989 & 0.988 \\
\hline Mid-foot width & 0.978 & 0.992 & 0.986 \\
\hline \multicolumn{4}{|l|}{ Heights } \\
\hline Medial malleolus height & 0.981 & 0.986 & 0.974 \\
\hline Lateral malleolus height & 0.992 & 0.986 & 0.996 \\
\hline Height at $50 \%$ foot length & 0.997 & 0.994 & 0.994 \\
\hline \multicolumn{4}{|l|}{ Girths } \\
\hline Ball girth & 0.995 & 0.991 & 0.991 \\
\hline Instep girth & 0.995 & 0.990 & 0.992 \\
\hline Long heel girth & 0.989 & 0.993 & 0.994 \\
\hline Short heel girth & 0.980 & 0.932 & 0.995 \\
\hline Ankle girth & 0.991 & 0.993 & 0.988 \\
\hline Waist girth & 0.992 & 0.996 & 0.994 \\
\hline
\end{tabular}

a ICC $(2,1)$ was used in our study, since all foot measurements were measured by the same operators, and they were assumed to be a random subset of all possible operators (Shrout and Fleiss, 1979);

b Inter-operator reliability was calculated from the mean of the two trials of operator 1 and operator 2;

c Intra-operator reliability was calculated for each operator respectively and used two trials data for each operator. 
Table 4. Descriptive statistics of all 18 measurements obtained from the three methods, $\mathrm{MM}, \mathrm{SM}$ and $\mathrm{CP}$ for the Training data set $(\mathrm{N}=10)$. All measurements in $\mathrm{mm}$

\begin{tabular}{|c|c|c|c|c|c|c|c|c|c|c|c|c|}
\hline \multirow[t]{2}{*}{ Foot Measurement } & \multicolumn{3}{|c|}{ Mean } & \multicolumn{3}{|c|}{ Max } & \multicolumn{3}{|c|}{ Min } & \multicolumn{3}{|c|}{ Std. dev. } \\
\hline & MM & SM & $\mathrm{CP}$ & MM & SM & $\mathrm{CP}$ & MM & SM & $\mathrm{CP}$ & MM & SM & $\mathrm{CP}$ \\
\hline Foot length & 250.6 & 250.2 & 249.3 & 274 & 273 & 271 & 231 & 231 & 230 & 12.7 & 13.1 & 13.3 \\
\hline Arch length & 183.3 & 183.5 & 181.1 & 198 & 197 & 195 & 164 & 164 & 162 & 9.7 & 9.7 & 9.7 \\
\hline Heel to medial malleolus & 61.4 & 61.7 & 59.3 & 71 & 73 & 70 & 51 & 53 & 51 & 5.8 & 6.3 & 5.8 \\
\hline Heel to lateral malleolus & 53.0 & 52.3 & 54.0 & 60 & 60 & 62 & 43 & 43 & 45 & 4.9 & 4.9 & 5.3 \\
\hline Foot width & 97.2 & 96.2 & 95.8 & 106 & 105 & 107 & 87 & 87 & 88 & 6.1 & 5.8 & 6.0 \\
\hline Medial malleolus height & 76.6 & 76.9 & 77.0 & 87 & 87 & 87 & 69 & 70 & 69 & 4.7 & 4.9 & 4.9 \\
\hline Lateral malleolus height & 65.7 & 65.2 & 65.4 & 75 & 74 & 74 & 54 & 55 & 55 & 6.2 & 5.6 & 5.7 \\
\hline Ball girth & 239.5 & 235.1 & 235.9 & 263 & 255 & 256 & 219 & 219 & 220 & 13.2 & 12.4 & 12.8 \\
\hline Instep girth & 247.5 & 242.8 & 245.2 & 277 & 263 & 272 & 222 & 215 & 221 & 15.0 & 15.7 & 16.3 \\
\hline Short heel girth & 314.5 & 311.3 & 313.6 & 350 & 346 & 348 & 289 & 290 & 294 & 17.4 & 17.3 & 17.6 \\
\hline Heel to $5^{\text {th }}$ toe & 202.6 & 202.7 & $* * *$ & 222 & 222 & $* * *$ & 191 & 192 & $* * *$ & 9.6 & 9.4 & $* * *$ \\
\hline Heel width & 65.4 & 63.9 & $* * *$ & 75 & 73 & $* * *$ & 59 & 58 & $* * *$ & 4.2 & 4.1 & $* * *$ \\
\hline Bimalleolar width & 68.5 & 67.4 & $* * *$ & 78 & 75 & $* * *$ & 61 & 60 & $* * *$ & 4.7 & 4.6 & $* * *$ \\
\hline Mid-foot width & 91.6 & 90.2 & $* * *$ & 104 & 101 & $* * *$ & 80 & 80 & $* * *$ & 6.7 & 6.4 & $* * *$ \\
\hline Height at $50 \%$ foot length & 60.6 & 62.6 & $* * *$ & 70 & 72 & $* * *$ & 51 & 53 & $* * *$ & 4.8 & 4.9 & $* * *$ \\
\hline Long heel girth & 336.4 & 336.2 & $* * *$ & 371 & 378 & $* * *$ & 311 & 304 & $* * *$ & 17.4 & 20.7 & $* * *$ \\
\hline Ankle girth & 248.7 & 242.6 & $* * *$ & 275 & 262 & $* * *$ & 229 & 226 & $* * *$ & 13.5 & 12.3 & $* * *$ \\
\hline Waist girth & 239.1 & 238.0 & $* * *$ & 260 & 259 & $* * *$ & 216 & 215 & $* * *$ & 14.0 & 14.0 & $* * *$ \\
\hline
\end{tabular}


Table 5. Descriptive statistics of all 18 measurements obtained from the three methods, MM, SM and CP for the Test data set $(\mathrm{N}=10)$. All measurements in $\mathrm{mm}$

\begin{tabular}{|c|c|c|c|c|c|c|c|c|c|c|c|c|}
\hline \multirow{2}{*}{ Foot Measurement } & \multicolumn{3}{|c|}{ Mean } & \multicolumn{3}{|c|}{ Max } & \multicolumn{3}{|c|}{ Min } & \multicolumn{3}{|c|}{ Std. dev. } \\
\hline & MM & $\mathrm{SM}$ & $\mathrm{CP}$ & MM & SM & $\mathrm{CP}$ & MM & $\mathrm{SM}$ & $\mathrm{CP}$ & $\mathrm{MM}$ & $\mathrm{SM}$ & $\mathrm{CP}$ \\
\hline Foot length & 246.7 & 246.2 & 245.1 & 271 & 269 & 268 & 226 & 226 & 226 & 12.3 & 12.6 & 12.5 \\
\hline Arch length & 179.3 & 179.3 & 176.7 & 197 & 196 & 195 & 164 & 164 & 163 & 9.5 & 9.4 & 9.3 \\
\hline Heel to medial malleolus & 59.3 & 60.0 & 57.5 & 69 & 70 & 68 & 47 & 49 & 48 & 6.3 & 6.9 & 6.5 \\
\hline Heel to lateral malleolus & 51.0 & 51.0 & 52.8 & 61 & 59 & 61 & 39 & 41 & 44 & 5.8 & 5.4 & 5.5 \\
\hline Foot width & 96.4 & 95.3 & 94.9 & 108 & 107 & 108 & 84 & 82 & 82 & 7.4 & 7.9 & 8.8 \\
\hline Medial malleolus height & 73.2 & 73.6 & 73.6 & 81 & 80 & 81 & 63 & 65 & 65 & 5.4 & 5.3 & 5.8 \\
\hline Lateral malleolus height & 61.8 & 61.2 & 61.2 & 75 & 75 & 75 & 52 & 51 & 51 & 6.7 & 7.1 & 7.5 \\
\hline Ball girth & 236.3 & 232.1 & 232.2 & 269 & 261 & 262 & 207 & 203 & 204 & 18.8 & 19.0 & 19.7 \\
\hline Instep girth & 239.1 & 233.1 & 235.5 & 273 & 275 & 274 & 209 & 202 & 209 & 18.9 & 19.8 & 21.8 \\
\hline Short heel girth & 307.5 & 305.3 & 307.1 & 337 & 338 & 338 & 279 & 279 & 281 & 19.2 & 19.7 & 19.9 \\
\hline Heel to $5^{\text {th }}$ toe & 199.7 & 198.9 & $* * *$ & 212 & 214 & $* * *$ & 179 & 179 & $* * *$ & 10.5 & 11.3 & $* * *$ \\
\hline Heel width & 63.5 & 61.5 & $* * *$ & 72 & 70 & $* * *$ & 57 & 55 & $* * *$ & 4.0 & 4.1 & $* * *$ \\
\hline Bimalleolar width & 67.1 & 65.6 & $* * *$ & 78 & 75 & $* * *$ & 61 & 60 & $* * *$ & 5.3 & 5.7 & $* * *$ \\
\hline Mid-foot width & 88.5 & 86.7 & $* * *$ & 105 & 103 & $* * *$ & 73 & 72 & $* * *$ & 9.5 & 9.5 & $* * *$ \\
\hline Height at $50 \%$ foot length & 58.6 & 60.5 & $* * *$ & 67 & 67 & $* * *$ & 49 & 52 & $* * *$ & 5.6 & 5.5 & $* * *$ \\
\hline Long heel girth & 327.3 & 326.2 & $* * *$ & 356 & 357 & $* * *$ & 302 & 288 & $* * *$ & 17.8 & 22.3 & $* * *$ \\
\hline Ankle girth & 245.1 & 239.8 & $* * *$ & 275 & 276 & $* * *$ & 216 & 215 & $* * *$ & 17.3 & 19.5 & $* * *$ \\
\hline Waist girth & 231.4 & 230.3 & $* * *$ & 270 & 271 & $* * *$ & 203 & 201 & $* * *$ & 20.9 & 22.6 & $* * *$ \\
\hline
\end{tabular}

Not available in CP 
Table 6. ANOVA and post-hoc Student-Newman-Keuls (SNK) tests for comparing three measurement methods $(\overline{M M}, \mathrm{SM}, \mathrm{CP})$ on 10 common measurements of training data set

\begin{tabular}{|c|c|c|c|c|c|}
\hline \multirow[t]{2}{*}{$\begin{array}{l}\text { Common foot } \\
\text { measurements }\end{array}$} & \multirow[t]{2}{*}{$\begin{array}{l}\text { Measurement method } \\
\text { effect (P-value) }\end{array}$} & \multicolumn{3}{|c|}{$\begin{array}{l}{ }^{\dagger} \text { SNK grouping } \\
\text { of measurement method }\end{array}$} & \\
\hline & & $\overline{M M}$ & 250.6 & $\mathrm{~A}$ & \\
\hline \multirow[t]{3}{*}{ Foot length } & $<0.0001^{*}$ & SM & 250.2 & $\mathrm{~A}$ & \\
\hline & & $\mathrm{CP}$ & 249.3 & $\mathrm{~B}$ & \\
\hline & & $\overline{M M}$ & 183.3 & $\mathrm{~A}$ & \\
\hline \multirow[t]{3}{*}{ Arch length } & $<0.0001^{*}$ & $\mathrm{SM}$ & 183.5 & $\mathrm{~A}$ & \\
\hline & & $\mathrm{CP}$ & 181.1 & $\mathrm{~B}$ & \\
\hline & & $\overline{\overline{M M}}$ & 61.4 & $\mathrm{~A}$ & \\
\hline \multirow[t]{3}{*}{ Heel to medial malleolus } & $<0.0001^{*}$ & SM & 61.7 & $\mathrm{~A}$ & \\
\hline & & $\mathrm{CP}$ & 59.3 & $\mathrm{~B}$ & \\
\hline & & $\overline{M M}$ & 53.0 & $\mathrm{~A}$ & \\
\hline \multirow[t]{3}{*}{ Heel to lateral malleolus } & $<0.0001^{*}$ & SM & 52.3 & B & \\
\hline & & $\mathrm{CP}$ & 54.0 & $\mathrm{C}$ & \\
\hline & & $\overline{M M}$ & 97.2 & $\mathrm{~A}$ & \\
\hline \multirow[t]{3}{*}{ Foot width } & $0.0252^{*}$ & SM & 96.2 & $\mathrm{~B}$ & \\
\hline & & $\mathrm{CP}$ & 95.8 & $\mathrm{~B}$ & \\
\hline & & $\overline{\overline{M M}}$ & 76.6 & $\mathrm{~A}$ & \\
\hline \multirow[t]{3}{*}{ Medial malleolus height } & 0.4418 & $\mathrm{SM}$ & 76.9 & $\mathrm{~A}$ & \\
\hline & & $\mathrm{CP}$ & 77.0 & $\mathrm{~A}$ & \\
\hline & & $\overline{\overline{M M}}$ & 65.7 & $\mathrm{~A}$ & \\
\hline \multirow[t]{3}{*}{ Lateral malleolus height } & 0.4607 & SM & 65.2 & $\mathrm{~A}$ & \\
\hline & & $\mathrm{CP}$ & 65.4 & $\mathrm{~A}$ & \\
\hline & & $\overline{\overline{M M}}$ & 239.5 & $\mathrm{~A}$ & \\
\hline \multirow[t]{3}{*}{ Ball girth } & $<0.0001^{*}$ & SM & 235.1 & $\mathrm{~B}$ & \\
\hline & & $\mathrm{CP}$ & 235.9 & $\mathrm{~B}$ & \\
\hline & & $\overline{\overline{M M}}$ & 247.5 & $\mathrm{~A}$ & \\
\hline \multirow[t]{3}{*}{ Instep girth } & $0.0263^{*}$ & SM & 242.8 & & $\mathrm{~B}$ \\
\hline & & $\mathrm{CP}$ & 245.2 & $\mathrm{~A}$ & $\mathrm{~B}$ \\
\hline & & $\overline{\overline{M M}}$ & 314.5 & $\mathrm{~A}$ & \\
\hline \multirow[t]{2}{*}{ Short heel girth } & $<0.0001^{*}$ & SM & 311.3 & B & \\
\hline & & $\mathrm{CP}$ & 313.6 & $\mathrm{~A}$ & \\
\hline
\end{tabular}

${ }^{\dagger}$ Means with the same letter (at right side of each cell) are not significantly different; ${ }^{*} \mathrm{P}<0.05$. 
Table 7. Differences between computerized measurement (SM, CP) and manual measurement $(\overline{M M})$ of the10 common measurements in training data set

\begin{tabular}{|c|c|c|c|c|c|}
\hline $\begin{array}{l}\text { Common foot } \\
\text { measurements }\end{array}$ & Differences & Mean & Maximum & Minimum & Std. dev. \\
\hline \multirow[t]{2}{*}{ Foot length } & $\mathrm{SM}-\overline{M M}$ & -0.32 & 0.52 & -1.09 & 0.63 \\
\hline & $\mathrm{CP}-\overline{M M}$ & -1.30 & 0.25 & -2.55 & 0.84 \\
\hline \multirow{2}{*}{ Arch length } & $\mathrm{SM}-\overline{M M}$ & 0.23 & 1.88 & -2.21 & 1.20 \\
\hline & $\mathrm{CP}-\overline{M M}$ & -2.15 & 0.70 & -5.30 & 1.80 \\
\hline \multirow{2}{*}{$\begin{array}{l}\text { Heel to medial } \\
\text { malleolus }\end{array}$} & $\mathrm{SM}-\overline{M M}$ & 0.24 & 3.67 & -1.68 & 1.59 \\
\hline & $\mathrm{CP}-\overline{M M}$ & -2.09 & 1.05 & -4.60 & 1.66 \\
\hline \multirow{2}{*}{$\begin{array}{l}\text { Heel to lateral } \\
\text { malleolus }\end{array}$} & $\mathrm{SM}-\overline{M M}$ & -0.72 & 0.86 & -3.64 & 1.20 \\
\hline & $\mathrm{CP}-\overline{M M}$ & 0.95 & 2.80 & -1.55 & 1.23 \\
\hline \multirow[t]{2}{*}{ Foot width } & $\mathrm{SM}-\overline{M M}$ & -0.92 & 0.56 & -3.41 & 1.21 \\
\hline & $\mathrm{CP}-\overline{M M}$ & -1.31 & 1.85 & -3.20 & 1.60 \\
\hline Malleolus & $\mathrm{SM}-\overline{M M}$ & 0.24 & 1.68 & -1.50 & 0.90 \\
\hline height (Medial) & $\mathrm{CP}-\overline{M M}$ & 0.35 & 1.60 & -0.60 & 0.74 \\
\hline Malleolus & $\mathrm{SM}-\overline{M M}$ & -0.50 & 1.16 & -2.85 & 1.27 \\
\hline height (Lateral) & $\mathrm{CP}-\overline{M M}$ & -0.24 & 1.90 & -2.75 & 1.49 \\
\hline \multirow[t]{2}{*}{ Ball girth } & $\mathrm{SM}-\overline{M M}$ & -4.39 & -1.69 & -8.21 & 1.96 \\
\hline & $\mathrm{CP}-\overline{M M}$ & -3.59 & -1.10 & -6.50 & 1.72 \\
\hline \multirow[t]{2}{*}{ Instep girth } & $\mathrm{SM}-\overline{M M}$ & -4.70 & 3.08 & -12.34 & 5.02 \\
\hline & $\mathrm{CP}-\overline{M M}$ & -2.29 & 3.65 & -7.95 & 3.17 \\
\hline \multirow[t]{2}{*}{ Short heel girth } & $\mathrm{SM}-\overline{M M}$ & -3.15 & -0.20 & -7.51 & 2.16 \\
\hline & $\mathrm{CP}-\overline{M M}$ & -0.84 & 1.35 & -4.55 & 1.87 \\
\hline
\end{tabular}


Table 8. Paired t-test results of differences (SM- $\overline{M M}$ ) of the 8 other measurements in training data set.

\begin{tabular}{lccccc}
\hline Foot measurements & Mean & Max & Min & Std. dev. & $\begin{array}{c}\text { P Value } \\
\text { (H0: Mean=0) }\end{array}$ \\
\hline Heel to $5^{\text {th }}$ toe & 0.12 & 1.81 & -3.92 & 1.71 & 0.8328 \\
\hline Heel width & -0.92 & 0.56 & -3.41 & 1.21 & $<0.0001^{*}$ \\
\hline Bimalleolar width & -1.08 & -0.04 & -2.15 & 0.66 & $0.0006^{*}$ \\
\hline Mid-foot width & -1.37 & -0.46 & -2.30 & 0.64 & $<0.0001^{*}$ \\
\hline Height at 50\% foot length & 2.00 & 3.09 & 1.28 & 0.53 & $<0.0001^{*}$ \\
\hline Long heel girth & -0.22 & 10.78 & -7.99 & 7.03 & 0.9227 \\
\hline Ankle girth & -6.09 & -3.61 & -10.59 & 2.52 & $<0.0001^{*}$ \\
\hline Waist girth & -1.09 & 2.93 & -4.32 & 2.32 & 0.1723 \\
\hline
\end{tabular}

${ }^{*} \mathrm{P}<0.05$ 
Table 9. Linear regression $\mathrm{SM}=\mathrm{a}^{*} \overline{M M}+\mathrm{b}$ and the hypothesis test of $\mathrm{a}=1$ for measurements that had significant differences between SM and $\overline{M M}$ in the training data set. (All measurements in $\mathrm{mm}$ )

\begin{tabular}{|c|c|c|c|}
\hline Foot measurements & $\begin{array}{l}\text { Linear regression equation } \\
\left(\mathrm{SM}=\mathbf{a}^{*} \overline{M M}+\mathbf{b}\right)\end{array}$ & $\mathbf{R}^{2}$ & $\begin{array}{l}\text { p Value } \\
\left(H_{0}: a=1\right)\end{array}$ \\
\hline \multicolumn{4}{|l|}{ Lengths } \\
\hline Heel to lateral malleolus & $\mathbf{S M}=1.0094 * \overline{M M}-1.222$ & 0.9428 & 0.9195 \\
\hline \multicolumn{4}{|l|}{ Widths } \\
\hline Foot width & $\mathbf{S M}=0.9333 * \overline{M M}+5.5601$ & 0.9643 & 0.3231 \\
\hline Heel width & $\mathbf{S M}=0.9823 * \overline{M M}-0.3071$ & 0.991 & 0.6095 \\
\hline Bimalleolar width & $\mathbf{S M}=0.9642 * \overline{M M}+1.3662$ & 0.9815 & 0.4645 \\
\hline Mid-foot width & $\mathbf{S M}=0.9480 * \overline{M M}+3.3884$ & 0.9934 & 0.0918 \\
\hline \multicolumn{4}{|l|}{ Heights } \\
\hline Height at $50 \%$ foot length & $\mathbf{S M}=1.0082 * \overline{M M}+1.507$ & 0.9888 & 0.8400 \\
\hline \multicolumn{4}{|l|}{ Girths } \\
\hline Ball girth & $\mathbf{S M}=0.9205 * \overline{M M}+14.653$ & 0.9835 & 0.0955 \\
\hline Instep girth & $\mathbf{S M}=0.9875 * \overline{M M}-1.6$ & 0.9034 & 0.9155 \\
\hline Short heel girth & $\mathbf{S M}=0.9876 * \overline{M M}+0.7566$ & 0.9853 & 0.7789 \\
\hline Ankle girth & $\mathbf{S M}=0.8929 * \overline{M M}+20.559$ & 0.9741 & 0.0710 \\
\hline
\end{tabular}


Table 10. Linear regression $\mathrm{SM}=\overline{M M}+\mathrm{b}$ for those measurements that had significant differences between SM, $\overline{M M}$ of training data set. (All measurements in mm)

\begin{tabular}{lll}
\hline Foot measurements & $\begin{array}{l}\text { Linear regression equation } \\
(\mathbf{S M}=\overline{M M}+\mathbf{b})\end{array}$ & $\mathbf{R}^{2}$ \\
\hline $\begin{array}{l}\text { Lengths } \\
\text { Heel to lateral malleolus }\end{array}$ & $\mathbf{S M}=\overline{M M}-0.720$ & 0.9427 \\
\hline Widths & $\mathbf{S M}=\overline{M M}-0.94$ & 0.9594 \\
Foot width & $\mathbf{S M}=\overline{M M}-1.465$ & 0.9906 \\
Heel width & $\mathbf{S M}=\overline{M M}-1.095$ & 0.9802 \\
Bimalleolar width & $\mathbf{S M}=\overline{M M}-1.400$ & 0.9904 \\
Mid-foot width & $\mathbf{S M}=\overline{M M}+2.005$ & 0.9887 \\
\hline Heights & $\mathbf{S M}=\overline{M M}-4.450$ & 0.9762 \\
Height at 50\% foot length & $\mathbf{S M}=\overline{M M}-4.700$ & 0.9032 \\
\hline Girths & $\mathbf{S M}=\overline{M M}-3.150$ & 0.9852 \\
Ball girth & $\mathbf{S M}=\overline{M M}-6.160$ & 0.9600 \\
Instep girth & & \\
Short heel girth & Ankle girth &
\end{tabular}


Table 11. ANOVA and post-hoc Student-Newman-Keuls (SNK) tests for comparing the three measurement methods ( $\overline{M M}$, adjusted $\mathrm{SM}^{\ddagger}, \mathrm{CP}$ ) on 10 common measurements of test data set

\begin{tabular}{|c|c|c|c|c|}
\hline \multirow[t]{2}{*}{$\begin{array}{l}\text { Common foot } \\
\text { measurements }\end{array}$} & \multirow[t]{2}{*}{$\begin{array}{l}\text { Measurement method } \\
\text { effect (P-value) }\end{array}$} & \multicolumn{3}{|c|}{$\begin{array}{l}{ }^{\dagger} \text { SNK grouping } \\
\text { Of measurement method }\end{array}$} \\
\hline & & $\overline{M M}$ & 246.7 & $\mathrm{~A}$ \\
\hline \multirow[t]{3}{*}{ Foot length } & $0.0001^{*}$ & SM & 246.2 & A \\
\hline & & $\mathrm{CP}$ & 245.1 & $\mathrm{~B}$ \\
\hline & & $\overline{M M}$ & 179.3 & $\mathrm{~A}$ \\
\hline \multirow[t]{3}{*}{ Arch length } & $<0.0001^{*}$ & SM & 179.4 & A \\
\hline & & $\mathrm{CP}$ & 176.7 & $\mathrm{~B}$ \\
\hline & & $\overline{M M}$ & 59.3 & $\mathrm{~A}$ \\
\hline \multirow[t]{3}{*}{ Heel to medial malleolus } & $<0.0001^{*}$ & SM & 60.0 & A \\
\hline & & $\mathrm{CP}$ & 57.5 & $\mathrm{~B}$ \\
\hline & & $\overline{M M}$ & 51.0 & $\mathrm{~A}$ \\
\hline \multirow[t]{3}{*}{ Heel to lateral malleolus } & $0.0002^{*}$ & Adjusted SM & 51.7 & A \\
\hline & & $\mathrm{CP}$ & 52.8 & $\mathrm{~B}$ \\
\hline & & $\overline{M M}$ & 96.4 & $\mathrm{~A}$ \\
\hline \multirow[t]{3}{*}{ Foot width } & $0.0078^{*}$ & Adjusted SM & 96.2 & A \\
\hline & & $\mathrm{CP}$ & 94.9 & $\mathrm{~B}$ \\
\hline & & $\overline{\overline{M M}}$ & 73.2 & $\mathrm{~A}$ \\
\hline \multirow[t]{3}{*}{ Medial malleolus height } & 0.2356 & SM & 73.6 & A \\
\hline & & $\mathrm{CP}$ & 73.6 & A \\
\hline & & $\overline{\overline{M M}}$ & 61.8 & A \\
\hline \multirow[t]{3}{*}{ Lateral malleolus height } & 0.4110 & SM & 61.2 & A \\
\hline & & $\mathrm{CP}$ & 61.2 & A \\
\hline & & $\overline{\overline{M M}}$ & 236.3 & A \\
\hline \multirow[t]{3}{*}{ Ball girth } & $<0.0001^{*}$ & Adjusted SM & 236.6 & A \\
\hline & & $\mathrm{CP}$ & 232.2 & $\mathrm{~B}$ \\
\hline & & $\overline{\overline{M M}}$ & 239.1 & $\mathrm{~A}$ \\
\hline \multirow[t]{3}{*}{ Instep girth } & 0.1513 & Adjusted SM & 237.9 & A \\
\hline & & $\mathrm{CP}$ & 235.5 & $\mathrm{~A}$ \\
\hline & & $\overline{\overline{M M}}$ & 307.5 & A B \\
\hline \multirow[t]{2}{*}{ Short heel girth } & $0.0340^{*}$ & Adjusted SM & 308.4 & $\mathrm{~A}$ \\
\hline & & $\mathrm{CP}$ & 307.1 & $\mathrm{~B}$ \\
\hline
\end{tabular}

$¥$ Original SM data was adjusted on heel to lateral malleolus, foot width, ball girth, instep girth and short heel girth;

${ }^{\dagger}$ Means with the same letter are not significantly different;

${ }^{*} \mathrm{P}<0.05$. 
Table 12. Paired t-test results of difference (adjusted $\mathrm{SM}^{\ddagger}-\overline{M M}$ ) on all 18 foot measurements of test data set

P Value

Foot measurements

Mean Maximum Minimum Std. dev.

(H0: Mean=0)

\begin{tabular}{lccccc}
\hline Lengths & & & & & \\
Foot length & -0.44 & 0.92 & -1.38 & 0.74 & 0.0922 \\
Arch length & 0.11 & 2.38 & -0.77 & 0.87 & 0.7100 \\
Heel to medial malleolus & 0.69 & 2.61 & -1.31 & 1.16 & 0.0950 \\
Heel to lateral malleolus & 0.73 & 2.69 & -1.54 & 1.27 & 0.1042 \\
Heel to 5 ${ }^{\text {th }}$ toe & -0.84 & 1.84 & -5.12 & 2.42 & 0.3034 \\
\hline Widths & & & & & \\
Foot width & -0.19 & 1.10 & -1.36 & 0.94 & 0.5332 \\
Heel width & -0.51 & 0.13 & -1.65 & 0.52 & $0.0123^{*}$ \\
Bimalleolar width & -0.37 & 0.55 & -1.67 & 0.70 & 0.1329 \\
Mid-foot width & -0.38 & 0.34 & -1.37 & 0.58 & 0.0678 \\
\hline Heights & & & & & \\
Medial malleolus height & 0.42 & 2.58 & -0.94 & 0.99 & 0.2142 \\
Lateral malleolus height & -0.57 & 1.02 & -3.32 & 1.31 & 0.1996 \\
Height at 50\% foot length & -0.12 & 0.38 & -1.04 & 0.48 & 0.4418 \\
\hline Girths & & & & & \\
Ball girth & 0.27 & 1.31 & -0.93 & 0.76 & 0.2860 \\
Instep girth & -1.13 & 7.78 & -13.99 & 6.79 & 0.6107 \\
Long heel girth & -1.20 & 11.43 & -18.71 & 9.98 & 0.7125 \\
Short heel girth & 0.97 & 3.49 & -1.67 & 1.85 & 0.1327 \\
Ankle girth & 0.85 & 7.73 & -3.19 & 3.27 & 0.4350 \\
Waist girth & -1.07 & 2.49 & -4.07 & 2.06 & 0.1338 \\
\hline & & & & \\
\hline
\end{tabular}

‡ Only measurements showing significant differences (listed in table 10) between original SM and MM were adjusted;

${ }^{*} \mathrm{P}<0.05$. 